NBER WORKING PAPER SERIES

\title{
A COMPARISON OF LINEAR AND NONLINEAR UNIVARIATE MODELS FOR FORECASTING MACROECONOMIC TIME SERIES
}

James H. Stock

Mark W. Watson

Working Paper 6607

http://www.nber.org/papers/w6607

\author{
NATIONAL BUREAU OF ECONOMIC RESEARCH \\ 1050 Massachusetts Avenue \\ Cambridge, MA 02138 \\ June 1998
}

This research was supported in part by National Science Foundation grant SBR 9409629. We benefited from comments on this wokr by Frank Diebold, Norm Swanson, Richard Zeckhauser, and members of the NECSI Time Series Working Group. Any opinions expressed are those of the author and not those of the National Bureau of Economic Research.

(C) 1998 by James H. Stock and Mark W. Watson. All rights reserved. Short sections of text, not to exceed two paragraphs, may be quoted without explicit permission provided that full credit, including (C) notice, is given to the source. 
A Comparison of Linear and Nonlinear

Univariate Models for Forecasting

Macroeconomic Time Series

James H. Stock and Mark W. Watson

NBER Working Paper No. 6607

June 1998

JEL \# C22, C32

\section{ABSTRACT}

A forecasting comparison is undertaken in which 49 univariate forecasting methods, plus various forecast pooling procedures, are used to forecast 215 U.S. monthly macroeconomic time series at three forecasting horizons over the period 1959 - 1996. All forecasts simulate real time implementation, that is, they are fully recursive. The forecasting methods are based on four classes of models: autoregressions (with and without unit root pretests), exponential smoothing, artificial neural networks, and smooth transition autoregressions. The best overall performance of a single method is achieved by autoregressions with unit root pretests, but this performance can be improved when it is combined with the forecasts from other methods.

James H. Stock

Kennedy School of Government

Harvard University

Cambridge, MA 02138

and NBER

James_Stock@harvard.edu
Mark W. Watson

Woodrow Wilson School

Princeton University

Princeton, NJ 08544-1013

and NBER

mwatson@princeton, edu 


\section{Introduction}

This paper addresses five specific questions in the context of forecasting U.S. macroeconomic time series. First, do nonlinear time series models produce forecasts that improve upon linear models in real time? Second, if there are benefits to using nonlinear models, are the benefits greatest for relatively tightly parameterized models or for more nonparametric approaches? Third, can forecasts at the six month or one year horizon be improved by using preliminary evidence on the persistence of the time series to select the forecasting model? Fourth, do combination forecasts outperform forecasts based on a single method across a range of time series, and if so how heavily should these combination forecasts weight the currently-best performing forecasting methods? Finally, are the gains from using these advanced methods over simple autoregressive forecasts large enough to justify their use, even by a risk-averse forecaster?

We conduct an experiment designed to answer these questions. In this experiment, various forecasts are compared at the one, six and twelve month horizons for 215 monthly U.S. economic time series. The experiment simulates real-time implementation of these methods, that is, all forecasts (including all parameter estimates, all model selection rules, all pretests, all forecast combining weights, etc.) are based exclusively on data through the date of each forecast. The parameter estimates, model selection statistics, pretests, and forecast combining weights, for all models are updated each month, and these updated statistics are used to make that month's simulated out of sample forecasts.

The forecasts studied here are produced by 49 forecasting methods. We refer to these as "methods" because many of these forecasts are based not on a single estimated model, but on results from multiple models that are subject to model selection criteria or pretests. We shall refer to the underlying individual models used by these forecasting methods as primitive models, of 
which there are a total of 121 . For example, one of our forecasting methods is an autoregression in levels with a constant term and lag order selection based on the Akaike Information Criterion (AIC), with lag length ranging from zero to twelve; in our terminology this forecasting method combines information from thirteen primitive models. The primitive models fall into four classes: autoregressions (AR), exponential smoothing (EX), artificial neural networks (ANN), and logistic smooth transition autoregressions (LSTAR). As an additional benchmark, a "no change" forecast was also considered.

We also consider various procedures to combine information from these 49 forecasting methods. We refer to these as forecast pooling procedures. Bates and Granger (1969), Granger and Newbold (1977), and Granger and Ramanathan (1984) demonstrated that averaging forecasts from different models can improve forecast performance when all the models are approximations. The pooling procedures considered here differ by the amount of weight placed on the model with the currently best performance, including weighting all the forecasts equally, weighting the forecasts in inverse proportion to their current mean squared error (MSE), using median forecasts, and placing all weight on the forecasting method that currently has the lowest simulated real-time MSE; this final pooling procedure is simulated real-time model selection by predictive least squares (PLS).

The forecasting methods used in this study have been chosen in part to facilitate comparison with other large-scale "horse races" among time series models. Makridakis et. al. (1982) studied performance of univariate methods in many series, some of which were economic time series, and concluded that exponential smoothing was often successful. Meese and Geweke (1984) compared various linear models using 150 macroeconomic time series and found that AR models with lag lengths selected by the AIC generally worked well. Interestingly, they also found that that linear combination forecasts did not appreciably improve forecast quality. More recently, in a model comparison exercise conducted under the auspices of the Santa Fe Institute, Weigand and 
Gershenfeld (1994) compared linear models with a large number of nonlinear models; although they detected nonlinear dynamics in several non-economic time series, the nonlinear forecasting models fared relatively poorly for the economic time series they considered (exchange rates). Swanson and White $(1995,1997)$ compared multivariate ANN models to linear vector autoregressions, and found that the vector autoregressions generally had lower MSEs than the ANN models in simulated real time (their models are all multivariate however so their study does not

compare directly to the exercise here). ${ }^{1}$ Relative to this literature, the contributions of our study include the use of a large number of macroeconomic time series, the use of a large number of nonlinear models, the investigation of unit root pretest methods, and an extensive investigation of forecast pooling procedures.

The remainder of this paper is organized as follows. The experimental design and forecasting models are given in section 2 . The data are described briefly in section 3 and in more detail in the Appendix. The results are presented and discussed in section 4, and conclusions are summarized in section 5 .

\section{Forecasting Methods and Experimental Design}

\subsection{General considerations}

Forecasting models. All the models investigated in this experiment are of the form,

$$
\mathrm{y}_{\mathrm{t}+\mathrm{h}}=\mathrm{f}_{\mathrm{i}}\left(\mathrm{Z}_{\mathrm{t}} ; \theta_{\mathrm{ih}}\right)+\mathrm{u}_{\mathrm{it}+\mathrm{h}}
$$

where $y_{t}$ is the series being forecast, $h$ is the forecast horizon, $i$ indexes the forecasting model $(i=1, \ldots, 121), \theta_{i h}$ is a vector of unknown parameters, $u_{i t}$ is an error term, and $Z_{t}$ is a vector of predictor variables. In general, $\mathrm{z}_{\mathrm{t}}=\left(\mathrm{y}_{\mathrm{t}}, \ldots, \mathrm{y}_{\mathrm{t}-\mathrm{p}}, \Delta \mathrm{y}_{\mathrm{t}}, \ldots, \Delta \mathrm{y}_{\mathrm{t}-\mathrm{p}}, 1, \mathrm{t}\right)$, where $\mathrm{p}$ is the maximal lag lengths. Typically, individual forecasting models use only a subset of the elements of $\mathrm{Z}_{\mathrm{t}}$. 
All forecasts are made fully recursively, that is, forecasts of $y_{t+h}$ are made using information in time periods $1,2, \ldots, \mathrm{t}$. For the forecast of $\mathrm{y}_{\mathrm{t}+\mathrm{h}}$, the parameter vector $\theta_{\mathrm{ih}}$ is estimated using the data $\left(y_{1}, y_{2}, \ldots, y_{t}\right)$. In all models, the parameter vector is estimated by minimizing the sum of squared residuals of the h-step ahead forecast, that is, the estimate of $\theta_{\mathrm{ih}}$ at time period $\mathrm{t}, \hat{\theta}_{\text {iht }}$,

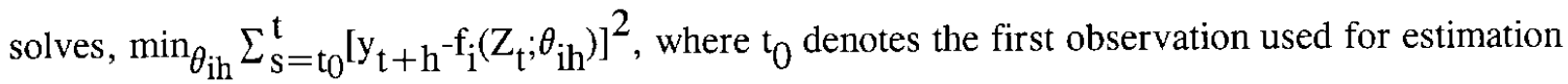
for that model.

Note that in general each forecasting method, applied to a particular series, has different parameter values at different horizons (that is, the h-period ahead forecast is not computed by iterating forward for $\mathrm{h}$ periods the one-period ahead forecasting model). This has costs and benefits. If the one-period ahead forecasting model is correct, then estimating it at the oneperiod horizon and iterating forward is more efficient than estimating the h-period ahead model directly. On the other hand, to the extent that the models are mispecified, estimating the hperiod ahead model directly permits the method to reduce the effects of the mispecification at the horizon at hand. From a practical perspective, forecasting the h-period ahead model directly requires more computer time for parameter estimation, but it simplifies considerably the computation of multistep forecasts from the nonlinear models.

The h-step ahead forecast and the forecast error are,

$$
\begin{aligned}
& y_{t+h \mid t, i h}=f_{i}\left(z_{t} ; \hat{\theta}_{i h t}\right) \\
& e_{t+h, i h}=y_{t+h}-y_{t+h \mid t, i h} .
\end{aligned}
$$

Forecast trimming. For our main results, all forecasts were automatically trimmed so that a forecasted change that exceeded in absolute value any change previously observed for that series was replaced by a no-change forecast. This adjustment was adopted to simulate the involvement of a human forecaster, who would be present in actual applications but is absent from our 
computerized experiment. Because the forecasts in this experiment are made automatically, some models could (and in fact do) make extreme forecasts. Possible sources of these extreme forecasts include parameter estimates that are local but not global maxima for the nonlinear models, parameter breaks, and errors arising from incorrect inclusion of deterministic trends. In true real time, such "crazy" forecasts arguably would be noticed and adjusted by human intervention. Accordingly, our forecast trimming algorithm can be thought of as a rule of thumb that a human forecaster might use in real time to detect and address such problems. Although we focus primarily on the trimmed forecasts, some results for the untrimmed forecasts are also presented for the purpose of comparison.

Startup and forecast periods. For each series, there are three separate periods: a startup period with which initial estimates of the model are produced; a intermediate period over which forecasts are produced by the 121 primitive models and 49 forecasting methods, but not by the pooling procedures; and the simulated real-time forecast period over which recursive forecasts are produced by all models, methods, and pooling procedures. Let $\mathrm{T}_{0}$ be the date of the first observation used in this study. Then the startup estimation period is $\mathrm{T}_{0}$ to $\mathrm{T}_{1}$, where $\mathrm{T}_{1}=\mathrm{T}_{0}+120$. The intermediate period is $T_{1}$ to $T_{2}-1$, where $T_{2}=T_{1}+24$. The forecast period is $T_{2}$ to $T_{3}$, where $\mathrm{T}_{3}$ is the date of the final observation (1996:12) minus the forecast horizon $\mathrm{h}$.

All forecast performance results reported in the tables are from the simulated real-time forecast period, $T_{2}$ to $T_{3}$ (inclusive). For most series, the initial observation date is 1959:1, in which case $\mathrm{T}_{0}=1959: 1, \mathrm{~T}_{1}=1970: 1, \mathrm{~T}_{2}=1972: 1$, and $\mathrm{T}_{3}=1996: 12-\mathrm{h}$.

\subsection{Forecasting models and methods}

The forecasting methods are listed in table 1. 
Autoregressive (AR) models. Results are reported for eighteen different autoregressive forecasting methods. These differ in their treatment of lag lengths ( 3 variants); in whether a constant, or a constant and a time trend, were included ( 2 variants); and in their treatment of persistence in the form of large autoregressive roots (3 variants).

Three alternative treatments of lag lengths were considered: a fixed lag length of 4 ; lag length determination by the BIC $(0 \leq \mathrm{p} \leq 12)$; and lag length determination by the AIC $(0 \leq \mathrm{p} \leq 12)$.

The possibility of persistence in the time series was handled by considering three alternatives. In the first, the autoregression was specified in levels, that is, $y_{t+h}$ was forecast using $y_{t}, \ldots, y_{t-p+1}$ with no restrictions on the coefficients. In the second, a unit root was imposed, so that the dependent variable was $\mathrm{y}_{\mathrm{t}+\mathrm{h}}-\mathrm{y}_{\mathrm{t}}$ and the predictors were $\Delta \mathrm{y}_{\mathrm{t}}, \ldots, \Delta \mathrm{y}_{\mathrm{t}-\mathrm{p}+1}$. In the third, a recursive unit root pretest was used to select between the levels or first differences specification. The unit root pretesting approach is widely used in practice, and many unit root tests statistics are available for this purpose. In a Monte Carlo study of unit root pretest autoregressive forecasts at moderate to long horizons, Stock (1996) compared several different pretest methods at various significance levels, and found that the best forecast performance across different values of the largest autoregressive root was obtained using the Elliott-Rothenberg-Stock (1996) DF-GLS test with a small signficance level. We therefore computed the unit root pretest using the DF-GLS ${ }^{\mu}$ statistic for the selection between models that included a constant term only. For selection between models that included a linear time trend under the levels alternative, the DF-GLS ${ }^{\tau}$ statistic was used. $^{2}$

In all, a total of 52 primitive autoregressive models were estimated ( 2 specifications of deterministic terms, 13 lag choices, in either levels or differences). The 18 forecasting methods based on these 52 primitive models include recursive model selection using information criteria and/or recursive unit root pretests, as detailed in table 1. 
For some of the results, it is useful to normalize the performance of the models by comparison to a naive method. Throughout, we use a simple autoregression as the naive method, specifically, an AR(4) (fixed lag length) in levels with a constant term.

Exponential Smoothing (EX). Two primitive exponential smoothing models are considered. Single or simple exponential smoothing forecasts are given by,

$$
\mathrm{y}_{\mathrm{t}+\mathrm{h} \mid \mathrm{t}}=\alpha \mathrm{y}_{\mathrm{t}+\mathrm{h}-1 \mid \mathrm{t}-1}+(1-\alpha) \mathrm{y}_{\mathrm{t}}
$$

Double exponential smoothing forecasts are given by,

$$
\begin{aligned}
& \mathrm{f}_{\mathrm{t}}=\alpha_{1}\left(\mathrm{f}_{\mathrm{t}-1}+\mathrm{g}_{\mathrm{t}-1}\right)+\left(1-\alpha_{1}\right) \mathrm{y}_{\mathrm{t}} \\
& \mathrm{g}_{\mathrm{t}}=\alpha_{2} \mathrm{~g}_{\mathrm{t}-1}+\left(1-\alpha_{2}\right)\left(\mathrm{f}_{\mathrm{t}}-\mathrm{f}_{\mathrm{t}-1}\right)
\end{aligned}
$$

where the forecast is $\mathrm{y}_{\mathrm{t}+\mathrm{h} \mid \mathrm{t}}=\mathrm{f}_{\mathrm{t}}+\mathrm{hg}_{\mathrm{t}}$. The parameters $\alpha$ in (2.4) and $\left(\alpha_{1}, \alpha_{2}\right)$ in (2.5) are estimated by recursive nonlinear least squares for each horizon.

Single exponential smoothing is conventionally intended for use with non-trending series, and double exponential smoothing is conventionally intended for trending series. We therefore considered a unit root pretest version of these two, in which either the single exponential smoothing forecast was used if the recursive DF-GLS ${ }^{\mu}$ pretest (described above) rejected the null of a unit root, else the double exponential smoothing forecast was used. The three forecasting methods based on these two primitive models therefore include the $\mathrm{I}(0)$ specification (2.4), the $\mathrm{I}(1)$ specification (2.5), and the specification selected by a recursive unit root pretest.

Artificial neural networks $(A N N)$. Neural network models with one and two hidden layers were considered. The single layer feedforward neural network models have the form, 


$$
\nu_{\mathrm{t}+\mathrm{h}}=\beta_{0}^{\prime} \zeta_{\mathrm{t}}+\sum_{\mathrm{i}=1}^{\mathrm{n}_{1}} \gamma_{1 \mathrm{i}} \mathrm{g}\left(\beta_{1 \mathrm{i}}^{\prime} \zeta_{\mathrm{t}}\right)+\mathrm{u}_{\mathrm{it}+\mathrm{h}}
$$

where $\mathrm{g}(\mathrm{z})$ is the logistic function, $\mathrm{g}(\mathrm{z})=1 /\left(1+\mathrm{e}^{\mathrm{z}}\right)$. When $\mathrm{y}_{\mathrm{t}}$ is modeled in levels, $\nu_{\mathrm{t}+\mathrm{h}}=\mathrm{y}_{\mathrm{t}+\mathrm{h}}$ and $\zeta_{\mathrm{t}}=\left(1, \mathrm{y}_{\mathrm{t}}, \mathrm{y}_{\mathrm{t}-1}, \ldots, \mathrm{y}_{\mathrm{t}-\mathrm{p}+1}\right)$. When $\mathrm{y}_{\mathrm{t}}$ is modeled in first differences, $v_{\mathrm{t}+\mathrm{h}}=\mathrm{y}_{\mathrm{t}+\mathrm{h}} \mathrm{y}_{\mathrm{t}}$ and $\zeta_{\mathrm{t}}=(1$, $\left.\Delta \mathrm{y}_{\mathrm{t}}, \Delta \mathrm{y}_{\mathrm{t}-1}, \ldots, \Delta \mathrm{y}_{\mathrm{t}-\mathrm{p}+1}\right)$. The neural network models with two hidden layers have the form,

$$
v_{\mathrm{t}+\mathrm{h}}=\beta_{0}^{\prime} \zeta_{\mathrm{t}}+\sum_{\mathrm{j}=1}^{\mathrm{n} 2} \gamma_{2 \mathrm{j}} \mathrm{g}\left[\sum_{\mathrm{i}=1}^{\mathrm{n}} \beta_{2 \mathrm{ji}} \mathrm{g}\left(\beta_{\mathrm{ii}}^{\prime} \zeta_{\mathrm{t}}\right)\right]+\mathrm{u}_{\mathrm{it}+\mathrm{h}} .
$$

Note that all the neural nets are forced to include a linear component. We will refer to (2.6) as having $n_{1}$ hidden units, and to (2.7) as having $n_{1}$ and $n_{2}$ hidden units, after removing a linear component. Alternatively, (2.6) could be thought of as having $n_{1}+1$ hidden units, with one of the hidden units forced to be linear.

The variants of (2.6) and (2.7) that are considered include different lag lengths p; the number of hidden units; and specification in levels and differences. The choices for single hidden layer ANNs are $n_{1}=\{1,2,3,4\}, p=\{1,3,6\}$, and levels/differences specification, for a total of 24 primitive models. (The restricted lag length choice of $p=\{1,3,6\}$ was used to reduce computational requirements.) The choices for ANNs with two hidden layers are $\mathrm{n}_{1}=2, \mathrm{n}_{2}=\{1,2\}, \mathrm{p}=\{1,3,6\}$, and levels/differences specification, comprising 12 primitive models. The 15 forecasting methods based on these 36 primitive models include recursive model selection using information criteria and/or recursive unit root pretests, as detailed in table 1.

In all models, coefficients were estimated by recursive nonlinear least squares. For these models, multiple local minima are an important concern, so the objective function was minimized using a combination of random search methods and local Gauss-Newton optimization. The initial parameter estimates at date $T_{1}$ were obtained as follows. The ANN models have a natural nesting 
from least complicated (fewest parameters) to most complicated. The most restrictive version of the model was estimated first. For the most restrictive versions of the models the objective function was evaluated using 5000 random draws of the parameter vector. The parameter vectors corresponding to the four smallest value of the objective function were then used as initial values for Gauss-Newton iterations, and the minimizer was chosen from the resulting set of parameters. This parameter vector together with 1000 additional random draws was used to evaluate the objective function associated with the next most complicated model; the parameter vectors associated with the two smallest values of the function were used to initialize the Gauss-Newton iterations. This procedure was repeated for each larger model in the nesting sequence. At subsequent dates $\left(\mathrm{T}_{1}<\mathrm{t} \leq \mathrm{T}_{3}\right)$, with probability .99 the parameter values were updated by taking three Gauss-Newton steps, using the parameter estimates from the previous date as starting values; with probability .01 the parameters were updated by using the minimum of these results and results obtained by completely reoptimizing from a set of 500 randomly selected initial parameter values (using the same method as at time $\mathrm{T}_{1}$ ).

Logistic smooth transition autoregressions (LSTAR). The LSTAR models that were considered had the form,

$$
\nu_{\mathrm{t}+\mathrm{h}}=\alpha^{\prime} \zeta_{\mathrm{t}}+\mathrm{d}_{\mathrm{t}} \beta^{\prime} \zeta_{\mathrm{t}}+\mathrm{u}_{\mathrm{t}+\mathrm{h}}
$$

where $\nu_{\mathrm{t}+\mathrm{h}}$ and $\zeta_{\mathrm{t}}$ are defined following (2.7) and $\mathrm{d}_{\mathrm{t}}=1 /\left(1+\exp \left[\gamma_{0}+\gamma_{1} \xi_{\mathrm{t}}\right]\right)$, where $\xi_{\mathrm{t}}$ is a function of current and past $y_{t}$ and is the variable used to define the smooth threshold.

The variants of the LSTAR models differ by the variable used to define the threshold; the specification in levels or differences or unit root pretest; and the lag length p. For models specified in levels, the following five alternatives were used for the threshold variable: $\xi_{t}=y_{t}$; 
$\xi_{\mathrm{t}}=\mathrm{y}_{\mathrm{t}-2} ; \quad \xi_{\mathrm{t}}=\mathrm{y}_{\mathrm{t}-5} ; \xi_{\mathrm{t}}=\mathrm{y}_{\mathrm{t}}-\mathrm{y}_{\mathrm{t}-6} ;$ and $\xi_{\mathrm{t}}=\mathrm{y}_{\mathrm{t}}-\mathrm{y}_{\mathrm{t}-12}$. For models specified in first differences, the following five alternatives were used for the threshold variable: $\xi_{\mathrm{t}}=\Delta \mathrm{y}_{\mathrm{t}} ; \xi_{\mathrm{t}}=\Delta \mathrm{y}_{\mathrm{t}-2} ; \xi_{\mathrm{t}}=\Delta \mathrm{y}_{\mathrm{t}-5}$; $\xi_{\mathrm{t}}=\mathrm{y}_{\mathrm{t}}-\mathrm{y}_{\mathrm{t}-6}$; and $\xi_{\mathrm{t}}=\mathrm{y}_{\mathrm{t}}-\mathrm{y}_{\mathrm{t}-12}$. In each case, lag lengths of $\mathrm{p}=\{1,3,6\}$ were considered, for a total of 30 primitive models (15 in levels, 15 in differences). The 12 forecasting methods based on these 30 primitive models include recursive model selection using information criteria and/or recursive unit root pretests, as detailed in table 1 .

The parameters $\alpha, \beta$ and $\gamma$ were estimated using the same random search/recursive GaussNewton optimization method as the artificial neural network models.

No change forecast. The no change forecast is $\mathrm{y}_{\mathrm{t}+\mathrm{h} \mid \mathrm{t}}=\mathrm{y}_{\mathrm{t}}$.

\subsection{Forecast Pooling Procedures}

Linear combination forecasts. Pooled forecasts were computed as weighted averages of the forecasts produced by the 49 forecasting methods. These combination forecasts have the form,

$$
\sum_{i=1}^{M} \kappa_{i h t} y_{t+h \mid t, i h} \text {, where } \kappa_{i h t}=\left(1 / \mathrm{MSE}_{i h t}\right)^{\omega} / \sum_{j=1}^{M}\left(1 / \mathrm{MSE}_{j h t}\right)^{\omega}
$$

where where i runs over the M methods and $\left\{\kappa_{\text {iht }}\right\}$ are the weights. The weighting schemes differ in the choice of $\omega$, how the MSE is computed, and the sets of methods that are combined. The simplest scheme places equal weight on all the forecasts, which corresponds to setting $\omega=0$ (in which case the MSE does not enter). As $\omega$ is increased, an increasing amount of emphasis is placed on those models that have been performing relatively well.

As shown by Bates and Granger (1969), if forecast error variances are finite then the optimal linear weighting scheme under quadratic loss involves the entire covariance matrix of forecast errors (see Granger and Newbold [1977]). With the large number of forecasts at hand, this scheme 
is impractical and would be unreliable because of the large number of covariances that would need to be estimated. Instead, we follow Bates and Granger's (1969) suggestion and drop the covariance term from our weighting expressions. Accordingly, the weights on the constituent forecasts are inversely proportional to their out-of-sample MSE, raised to the power $\omega$. The weights with $\omega=1$ correspond to Bates and Granger's (1969) suggestion. We also explore the possibility that more weight should be placed on the best performing models than would be indicated by inverse MSE weights, and this is achieved by considering $\omega>1$. Note that when $\omega \neq 0$ the weights $\left\{\kappa_{\mathrm{iht}}\right\}$ differ from series to series.

Bates and Granger (1969) also stress that the relative performance of different models can change over time. This suggests computing MSEs over rolling windows. The MSEs were therefore computed in three ways: over 60 and 120 period rolling windows (more precisely, over the past $\min \left(\mathrm{t}-\mathrm{T}_{1}+1,60\right)$ or $\min \left(\mathrm{t}-\mathrm{T}_{1}+1,120\right)$ periods, respectively), and recursively (over the past $\mathrm{t}-\mathrm{T}_{1}+1$ periods).

The averages were computed over three different sets of forecasts: the linear methods (AR and EX); the nonlinear methods (ANN and LSTAR); and all the methods discussed above (linear, nonlinear, and no change).

Median combination forecasts. If forecast errors are nonGaussian then linear combinations are no longer optimal. We therefore consider combination forecasts constructed as the median from a group of methods. In practice this guards against placing weight on forecasts that are badly wrong for method-specific reasons such as parameter breaks or parameter estimates achieving local but not global optima. The medians were computed over three different sets of forecasts: linear (AR and EX); nonlinear (ANN and LSTAR); and all the methods discussed above (linear, nonlinear, and no change). This median forecasts can be thought of as a consensus forecasts obtained by a vote of a panel of experts, where each expert (forecasting method) gets one vote: the consensus forecast is achieved when half the experts are on each side of the forecast. 
Predictive least squares (PLS) forecasts. An alternative approach to pooling forecast information is to select the model that has produced the best forecasts (as measured by the lowest out-of-sample MSE) up to the forecast date. This constitutes selection across these models by predictive least squares. The PLS forecasts differ by the period over which the PLS criterion is computed and the sets of models for which it is computed.

The periods for which the PLS forecast were computed are the same as for the combination forecasts, specifically, over the past $\min \left(\mathrm{t}-\mathrm{T}_{1}+1,60\right)$ periods; over the past $\min \left(\mathrm{t}-\mathrm{T}_{1}+1,120\right)$ periods; and over the past $\mathrm{t}-\mathrm{T}_{1}+1$ periods.

The PLS forecasts were computed for five sets of models: all 49 models listed in Table 1 under the categories AR, EX, ANN, LSTAR, NOCHANGE; all linear models listed in table 1 (AR and EX); all nonlinear models listed in table 1 (ANN and LSTAR); all 121 primitive models; and all 49 methods plus all other linear combination, median, and PLS pooling forecasts. The purpose of examining this final group is to see whether the potential optimality of pooled forecasts could have been ascertained empirically in (simulated) real time.

\section{Data}

The data are monthly U.S. macroeconomic time series. The series fall into the following general categories: production (including personal income), employment and unemployment, wages (hours and earnings), construction (including housing starts), trade (wholesale and retail), inventories, orders, money and credit, stock returns, stock market dividends and volume, interest rates, exchange rates, producer price inflation, consumer price inflation, consumption, and miscellaneous (e.g. consumer confidence). 
Some of these series were subjected to preliminary transformations. The series in dollars, real quantities and price deflators were transformed to their logarithms. Most other series (interest rates, the unemployment rate, exchange rates, etc.) were left in their native units.

In general, the first date used is either the first date for which the series is available or 1959:1, whichever is later. The exception to this rule is exchange rates; because exchange rates are essentially flat in the fixed exchange rate period, following Meese and Rogoff (1983) the first observation used for exchange rates is 1973:1.

A complete list of the series, their sources, the initial observation date used, and the transformation used are given in the Appendix.

\section{Results}

\subsection{Description of Tables}

Table 2 contains statistics summarizing the performance of each forecasting method, relative to the naive method (an AR(4) specified with a constant term in levels). For each series, forecast method and horizon, the mean square of the $\mathrm{T}_{3}-\mathrm{T}_{2}+1$ simulated out-of-sample forecast errors was computed; for forecasting method $\mathrm{i}$, denote this $\mathrm{MSE}_{\mathrm{ij}, \mathrm{h}}, \mathrm{j}=1, \ldots, 215$ and $\mathrm{h}=1,6,12$. The relative mean square forecast error of the $\mathrm{i}$-th forecasting method is $\mathrm{MSE}_{\mathrm{ij}, \mathrm{h}} / \mathrm{MSE}_{1 \mathrm{j}, \mathrm{h}}$, where $\mathrm{i}=1$ corresponds to the naive $\operatorname{AR}(4)$ forecast. Table 2 contains the averages and empirical quantiles of the distribution (across series) of this relative MSE, for each of $49 \mathrm{AR}, \mathrm{EX}$, No change, ANN, and LSTAR methods listed in table 1, and for various pooled forecasts. If, for example, the median of this distribution exceeds one for a candidate forecasting model and horizon, then for at least half the series the naive method had a lower simulated out-of-sample MSE at that horizon than the candidate forecasting model.

Table 3 compares forecasting methods by presenting the fraction of series for which each forecasting method is among the top $\mathrm{N}$ methods for various values of $\mathrm{N}$. The forecasts compared 
in this table consist of the 49 methods in groups $\mathrm{A}, \mathrm{B}$ and $\mathrm{C}$ in table 1 , plus the 14 pooling procedures for which results are reported in table 3 . For example, at horizon $h=1$, for $4 \%$ of the series, the ARFCO4 method (which is the naive method used in table 2) had the lowest simulated out-of-sample MSE of all the forecasting methods; for $17 \%$ of the series, its MSE was among the lowest five.

A natural question to ask in this comparison is which forecasting method is best overall. The answer to this question depends, among other things, on the attitude towards risk of the forecaster, that is, on the forecaster's loss function. Table 4 therefore reports rankings of the different methods for different loss functions. The loss functions are all of the form,

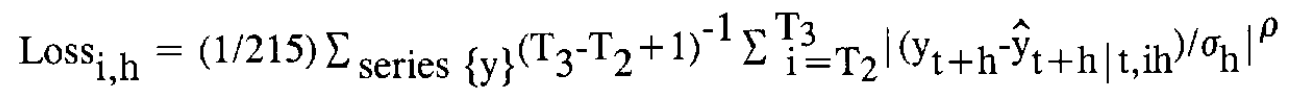

where $\sigma_{\mathrm{h}}$ is the estimated standard deviation of $\mathrm{y}_{\mathrm{t}}+\mathrm{h}^{-\mathrm{y}_{\mathrm{t}}}$.

\subsection{Discussion of Results}

We now turn to a summary of some of the main features of the results.

Unit root pretests. Pretesting for unit roots generally improves performance at all horizons, as measured by mean or median relative MSEs in table 2. Among AR models, this improvement is most pronounced when the levels specification includes a time trend. This improvement is also pronounced for the EX and ANN models. Evidently both ARs in levels with time trends and the ANN models in levels can produce forecasts that are quite poor, and pretesting to identify situations in which a unit root can be imposed reduces the frequency of extreme errors.

AIC- and BIC-based model selection. The performance of automatic lag length selection methods depends on the family of models being used, and it does not seem possible to reach 
general conclusions. Among autoregressions, average automatic order selection yields only marginal improvements over the naive imposition of 4 lags. Comparisons of AIC and BIC lag length choice for comparable autoregressive models indicates that BIC lag choice has somewhat lower MSEs than AIC-based methods. Among ANNs forecast performance was also best when the BIC was used. Among LSTARs, neither the AIC nor the BIC methods have mean, median, or extreme relative MSEs as good as some of the fixed methods (in particular the LS1063 and LSP063 methods).

On average, the MSE improvement over the naive method from using data-based model selection methods are modest. For example, adopting BIC lag selection and unit root pretesting in an autoregression with a constant results in a mean relative MSE of 1.00 for $\mathrm{h}=1,0.96$ for $\mathrm{h}=6$, and 0.98 for $h=12$. However, for some series, large MSE gains are possible, relative to the naive forecast. For example, in $2 \%$ of series, MSE reductions of amost two-thirds were achieved at the 12 month horizon by introducing BIC lag selection and unit root pretests to the naive method. Comparison of the ARFC04, ARFCOb, ARFCP4, and ARFCPb results in table 2 clearly show that most of these gains are achieved by the unit root pretest rather than AIC lag selection.

Performance of simple methods. The simplest methods performed poorly relative to the naive AR(4) method. For example, for approximately $75 \%$ of series, the no change forecast was worse than the naive forecast at all three horizons. The exponential smoothing method EX1 was badly wrong for some series, and on average all exponential smoothing methods have relative MSEs exceeding one at all horizons.

ANN methods. Generally speaking, the ANN methods all performed poorly. The ANN methods are rarely among the top ten methods for a given series (table 3). All have mean and median relative MSEs exceeding one at all horizons. Although improvements are obtained for 
some series, all the ANN methods perform quite poorly for a small fraction of the series: for all ANN methods the $98 \%$ percentile of the relative MSE exceeds 2 for some horizon. The performance varies among ANN methods. The ANN methods specified in levels generally perform quite poorly. Interestingly, adding a second hidden layer generally results in worse performance, as measured by the relative MSEs. This generally poor performance of feedforward ANN methods for economic data is consistent with the findings in Swanson and White (1995, 1997) and Weigand and Gershenfeld (1994).

LSTAR methods. Although the LSTAR methods were rarely best for any series, in some cases they provided MSE improvements, relative to the naive method. The best-performing LSTAR methods were the LS1063 and its pretest variant LSP063. Although both have mean relative MSEs exceeding one, their median relative MSEs are less than one at the six month horizon. The LSTAR methods generally outperformed the ANN methods.

Forecast pooling. One of the striking features in tables 2-4 is the strong performance of various forecast pooling procedures Simple average forecasts, forecasts weighted by inverse MSEs, and the median forecasts outperform the naive method. Indeed, based on the loss function comparisons in table 4 , the most attractive forecast is the simple average of the forecasts from all methods. Among the various weighting schemes, simple averaging and weighting by inverse MSEs produce similar performance. Performance, as measured by mean relative MSE, deterioriates as $\omega$ increases, especially at long horizons. In fact, performance of the PLS forecasts, which are the limit as $\omega \rightarrow \infty$ of the weighted average forecasts, is worse than all weighted average forecasts and the median forecast. As measured by average relative MSEs, the PLS forecasts are never better than the naive forecast. Use of a shortened window (60 or 120 months) seems to have little effect on the combination forecasts based on inverse MSE weights; although the relative MSE is least for the 120 month rolling window, the reduction is small. 
The pooling procedures that combine forecasts from all 49 methods have a slight edge over these procedures applied to only the linear, or only the nonlinear, methods. Indeed, for at least one-half of the series at all three horizons, the equal-weighted linear combination forecast that averages the forecasts from all 49 methods produces forecasts that are among the top ten in table 3.

Sensitivity to forecaster attitudes towards risk. A wide range of risk parameters $\rho$ are presented in table 4, ranging from mean absolute error loss to mean cubic absolute error loss. Mean absolute error loss characterizes a forecaster who is equally concerned about small and large errors; cubic loss most heavily penalizes large errors.

The rankings among the various methods are surprisingly insensitive to the choice of risk parameter $\rho$. Linear combination procedures minimize average loss for all values of $\rho$ considered. Indeed, for all values of $\rho$ and for all horizons, the loss minimizing forecast is produced by the simple average computed over all 49 methods.

Table 4 establishes a clear ranking of classes of models and procedures, with combination forecasts first, followed by AR forecasts, followed by LSTAR forecasts, followed by ANN forecasts, followed by EX and No Change. If pooling procedures are excluded, the best method is an autoregression based on a unit root pretest; whether fixed lags or data-dependent lag lengths are preferable depends on the forecast horizon.

Effect of forecast trimming. All results discussed so far are based on trimmed forecasts. The results for some methods are very different when the forecasts are not trimmed. The effects of trimming are most important for the nonlinear methods, which for some series produce forecasts that are off by two or more orders of magnitude. The trimming also considerably improves AR forecasts in levels with a time trend. 
For comparison purposes, the rankings for the various forecasting methods based on the untrimmed forecasts are given in table 5. The differences between the rankings based on the trimmed (table 4) and untrimmed (table 5) forecasts are attributable to the relatively few extremely large forecast errors made by the nonlinear methods and, to a lesser degree, by the AR methods in levels with time trends. Because of the few large errors, the median pooled forecasts are optimal for the untrimmed forecasts, and because the large errors are concentrated in the nonlinear methods, the linear combination forecasts perform well only when computed over just the linear methods.

The rankings of the individual methods change somewhat for the untrimmed forecasts. Autoregressive methods work well if the series is specified in levels with a constant, in first differences with a constant and/or time trend, or if a pretest is used, but they work poorly for the levels/time trend specification. Exponential smoothing and No Change methods rank relatively higher because they produce fewer extreme errors. Among nonlinear methods, the best ranking at any horizon is for ANFPb, which is twenty-first for the least risk averse value of $\rho(\rho=1)$ at $h=12$.

Nonlinearities across groups of series. The relative performance of linear and nonlinear methods is explored in table 6 . The first three columns compare the relative performance of the best AR, the best ANN, and the best LSTAR methods (where best is determined by recursive PLS within that class of methods) by reporting the fraction of times that this forecast is best for the category of series specified in that row, by horizon. The final two columns contain a similar comparison, computed for the two linear combination forecasts respectively based on the linear and nonlinear methods (in both cases, weights are recursive inverse MSE).

The results suggest that the importance of nonlinearities differs across series. The nonlinear methods have the greatest relative success for wages, employment, and exchange rates especially at long horizons, and the least success for inventories, trade, consumption, stock prices. Exchange 
rates are interesting because the nonlinear combination forecast outperforms the linear combination forecast at the longer horizons for four of the six exchange rates. This is in some contrast to previous studies which have found limited ability of nonlinear models to forecast exchange rates (Brooks [1997]). There seems to be no apparent pattern in the relative performance of nonlinear and linear methods over horizons. Consistent with the previous findings, the ANN methods generally are not the best; of the nonlinear methods, the LSTAR forecasts are first much more often.

\section{Conclusion}

Several caveats are in order prior to drawing conclusions from this study. Although a large number of methods have been considered, we have only considered two classes of nonlinear methods, and within artificial neural networks we have only considered feedforward neural nets. It is possible that other nonlinear methods, for example recurrent neural nets, could perform better than those considered here. Also, these results are subject to sampling error. Although the design has carefully adhered to a recursive (simulated real time) structure, because there are many forecasting methods considered, the estimated performance of the best-performing single method for these data arguably overstates the population counterpart of this performance measure. This criticism is less likely to be a concern, however, for the combination forecasts. Finally, it is unlikely that the best performing forecasts could have been identified as such in real time. When PLS was applied to all forecasts (including all the combination forecasts), the resulting PLS forecasts (PA060, PA120 and PA999) performed considerably worse than the best combination forecast, and indeed on average it performed worse than the naive method as measured by its mean relative MSE. 
One question is whether the limited evidence in favor of nonlinear methods found here is an artifact of seasonal adjustment. It is known that seasonal adjustment procedures are nonlinear filters, and Ghysels, Granger and Siklos (1996) showed that for Census X-11 these nonlinearities are sufficiently important that they can be detected with nontrivial power using various tests for nonlinearities. The focus here has been on forecast MSE reduction rather than tests for nonlinearities, but presumably some of the forecast MSE reduction of linear methods could be attributable to seasonal adjustment. It should be borne in mind that, were this the case, its implications are not self-evident. On the one hand, to the extent that we are interested in empirical evidence of nonlinear dynamics to guide theoretical macroeconomic modeling, then it is important to know if these nonlinearities are spuriously introduced by seasonal adjustment. On the other hand, if our interest is in forecasting seasonally adjusted series, the source of the nonlinearity is of only academic interest and the relevant question is which forecasting method best handles this nonlinearity.

Bearing these comments in mind, we turn to the implications of this forecasting experiment for the five questions raised in the introduction.

First, although some of the nonlinear forecasts improve upon the linear forecasts for some series, most of the nonlinear forecasting methods, and all of the neural network methods, produce worse forecasts than the linear methods. Overall, AR methods have lower average cost than the LSTAR or ANN methods.

Second, to the extent that the nonlinear forecasts improve upon the linear forecasts, the methods that do so are relatively tightly parameterized. In particular, the LSTAR methods generally outperform the feedforward ANN methods, either with one or two hidden layers. Interestingly, specification testing over LSTAR methods using the AIC or BIC does not seem to produce reliable improvements over the best fixed LSTAR method. 
Third, forecasts at all horizons are improved by unit root pretests. Severe forecast errors are made in nonlinear methods specified in levels and in linear methods in levels with time trends, and these errors are reduced substantially by preliminary testing for a unit root.

Fourth, pooled forecasts, in particular linear combination and median forecasts, were found to outperform the forecasts from any single method. The pooling procedures that place weight on all forecasting methods (whether equal weighting, inverse MSE weighting, or median) proved most reliable, while those that emphasized the recently best performing methods (especially PLS) proved least reliable. At the twelve month horizon, the mean relative MSE of the pooled forecast, computed by simple averaging of all 49 methods is .89 , and the $2 \%$ percentile relative MSE is 26 . There was little effect (positive or negative) of using a reduced or rolling sample for computing the combination weights.

Fifth, the gains from using combination forecasts were sufficiently large to justify their use by a risk-averse forecaster. If, however, a macroeconomic forecaster is restricted to using a single method, then for the family of loss functions considered here she would be well advised to use an autoregression with a unit root pretest and data-dependent lag length selection. 


\section{Footnotes}

1. It should be emphasized that, like the experiment reported in this paper, these studies are simulated real time exercises, not a comparison of true real time forecasts. True real-time forecasts are based on preliminary data and often contain significant judgmental adjustments; see for example McNees $(1986,1990)$ and the surveys in Granger and Newbold (1977, ch. 8.4 and 1986, ch. 9.4). Although true out of sample MSEs would differ from those reported here, the simulated real time nature of this experiment provides a controlled environment for comparing and ranking different forecasting methods.

2. A fixed lag length of six was used to compute the unit root test statistics. The unit root pretests were computed and applied recursively, that is, the forecast of $y_{t}+h$ using data through time $t$ were computed using the model selected at time $t$ by the unit root pretest computed using data through time $t$. The critical values for the unit root tests were chosen so that the pretest constituted a consistent rule for selecting between the $\mathrm{I}(0)$ and $\mathrm{I}(1)$ specification. Specifically, for the DF-GLS ${ }^{\mu}$ test, the critical value was $\ln (120 / \mathrm{t})-1.95$, and for the DF-GLS ${ }^{\tau}$ test the critical value was $\ln (120 / t)-2.89$. When $t=120$, these correspond to $5 \%$ significance level unit root pretests, with lower significance levels as the sample size increases. 


\section{Appendix: Data Description}

This appendix lists the time series used. The data were obtained from the DRI BASIC

Economics Database (creation date 9/97). The format for each series is its DRI BASIC

mnemonic; a brief description; and the first date used (in brackets). A series that was

preliminarily transformed by taking its logarithm is denoted by "log" in parentheses; otherwise,

the series was used without preliminary transformation. Abbreviations: sa=seasonally adjusted;

saar $=$ seassonally adjusted at an annual rate; nsa=not seasonally adjusted.

IP industrial production: total index $(1992=100$, sa) [1959:1] $(\log )$

IPP industrial production: products, total $(1992=100, \mathrm{sa})[1959: 1](\log )$

IPF industrial production: final products $(1992=100, \mathrm{sa})[1959: 1](\log )$

IPC industrial production: consumer goods $(1992=100$, sa $)$ [1959:1] (log)

IPCD industrial production: durable consumer goods $(1992=100, \mathrm{sa})[1959: 1](\log )$

IPCN industrial production: nondurable condsumer goods $(1992=100$, sa) [1959:1] (log)

IPE industrial production: business equipment $(1992=100, \mathrm{sa})[1959: 1](\log )$

IPI industrial production: intermediate products $(1992=100, \mathrm{sa})[1959: 1]$ (log)

IPM industrial production: materials $(1992=100, \mathrm{sa})[1959: 1](\mathrm{log})$

IPMD industrial production: durable goods materials $(1992=100, \mathrm{sa})$ [1959:1] $(\log )$

IPMND industrial production: nondurable goods materials $(1992=100, \mathrm{sa})[1959: 1](\mathrm{log})$

IPMFG industrial production: manufacturing $(1992=100$,sa) [1959:1] $(\log )$

IPD industrial production: durable manufacturing $(1992=100, \mathrm{sa})[1959: 1](\log )$

IPN industrial production: nondurable manufacturing $(1992=100, \mathrm{sa})[1959: 1](\log )$

IPMIN industrial production: mining $(1992=100, \mathrm{sa})[1959: 1](\log )$

IPUT industrial production: utilities $(1992-=100, \mathrm{sa})[1959: 1](\log )$

IPX capacity util rate: total industry (\% of capacity,sa)(frb) [1967:1]

IPXMCA capacity util rate: manufacturing,total(\% of capacity,sa)(frb) [1959:1]

IPXDCA capacity util rate: durable mfg (\% of capacity,sa)(frb) [1967:1]

IPXNCA capacity util rate: nondurable mfg (\% of capacity,sa)(frb) [1967:1]

IPXMIN capacity util rate: mining (\% of capacity,sa)(frb) [1967:1]

IPXUT capacity util rate: utilities (\% of capacity,sa)(frb) [1967:1]

LHEL index of help-wanted advertising in newspapers $(1967=100 ; \mathrm{sa})$ [1959:1]

LHELX employment: ratio; help-wanted ads:no. unemployed clf [1959:1]

LHEM civilian labor force: employed, total (thous., sa) [1959:1] (log)

LHNAG civilian labor force: employed, nonagric.industries (thous., sa) [1959:1] (log)

LHUR unemployment rate: all workers, 16 years \& over $(\%$, sa) [1959:1]

LHU680 unemploy.by duration: average(mean)duration in weeks (sa) [1959:1]

LHU5 unemploy.by duration: persons unempl.less than 5 wks (thous., sa) [1959:1] (log)

LHU14 unemploy.by duration: persons unempl.5 to 14 wks (thous. , sa) [1959:1] (log)

LHU15 unemploy.by duration: persons unempl.15 wks + (thous., sa) [1959:1] (log)

LHU26 unemploy.by duration: persons unempl.15 to 26 wks (thous., sa) [1959:1] (log)

LHU27 unemploy.by duration: persons unempl.27 wks + (thous,sa) [1959:1] (log) 
LHCH average hours of work per week (household data)(sa) [1959:1]

LPNAG employees on nonag. payrolls: total (thous., sa) [1959:1] $(\log )$

LP employees on nonag payrolls: total, private (thous, sa) [1959:1] $(\log )$

LPGD employees on nonag. payrolls: goods-producing (thous., sa) [1959:1] (log)

LPMI employees on nonag. payrolls: mining (thous. ,sa) [1959:1] (log)

LPCC employees on nonag. payrolls: contract construction (thous., sa) [1959:1] (log)

LPEM employees on nonag. payrolls: manufacturing (thous., sa) [1959:1] (log)

LPED employees on nonag. payrolls: durable goods (thous., sa) [1959:1] (log)

LPEN employees on nonag. payrolls: nondurable goods (thous., sa) [1959:1] (log)

LPSP employees on nonag. payrolls: service-producing (thous., sa) [1959:1] (log)

LPTU employees on nonag. payrolls: trans. \& public utilities (thous., sa) [1959:1] (log)

LPT employees on nonag. payrolls: wholesale \& retail trade (thous.,sa) [1959:1] (log)

LPFR employees on nonag. payrolls: finance, insur.\&real estate (thous., sa [1959:1] (log)

LPS employees on nonag. payrolls: services (thous., sa) [1959:1] (log)

LPGOV employees on nonag. payrolls: government (thous., sa) [1959:1] (log)

LW avg. weekly hrs. of prod. wkrs.: total private (sa) [1964:1]

LPHRM avg. weekly hrs. of production wkrs.: manufacturing (sa) [1959:1]

LPMOSA avg. [1959:1]

LEH avg hr earnings of prod wkrs: total private nonagric (\$,sa) [1964:1] (log)

LEHCC avg hr earnings of constr wkrs: construction (\$,sa) [1959:1] (log)

LEHM avg hr earnings of prod wkrs: manufacturing $(\$$, sa) [1959:1] (log)

LEHTU avg hr earnings of nonsupv wkrs: trans \& public util(\$,sa) [1964:1] (log)

LEHTT avg hr earnings of prod wkrs: wholesale \& retail trade(sa) [1964:1] (log)

LEHFR avg hr earnings of nonsupv wkrs: finance, insur, real est(\$,sa) [1964:1] (log)

LEHS avg hr earnings of nonsupv wkrs: services $(\$, \mathrm{sa})[1964: 1](\log )$

HSFR housing starts:nonfarm(1947-58); total farm\&nonfarm(1959-)(thous., sa [1959:1] (log)

HSNE housing starts:northeast (thous.u.)s.a. [1959:1] (log)

HSMW housing starts:midwest(thous.u.)s.a. [1959:1] (log)

HSSOU housing starts:south (thous.u.)s.a. [1959:1] (log)

HSWST housing starts:west (thous.u.)s.a. [1959:1] (log)

HSBR housing authorized: total new priv housing units (thous., saar) [1959:1] (log)

HSBNE houses authorized by build. permits:northeast(thou.u.)s.a [1960:1] (log)

HSBMW houses authorized by build. permits:midwest(thou.u.)s.a. [1960:1] (log)

HSBSOU houses authorized by build. permits:south(thou.u.)s.a. [1960:1] (log)

HSBWST houses authorized by build. permits:west(thou.u.)s.a. [1960:1] (log)

HNS new 1-family houses sold during month (thous, saar) [1963:1] (log)

HNSNE one-family houses sold:northeast(thou.u.,s.a.) [1973:1] (log)

HNSMW one-family houses sold:midwest(thou.u.,s.a.) [1973:1] (log)

HNSSOU one-family houses sold:south(thou.u.,s.a.) [1973:1] (log)

HNSWST one-family houses sold:west(thou.u., s.a.) [1973:1] (log)

HNR new 1-family houses, month's supply @ current sales rate(ratio) [1963:1]

HMOB mobile homes: manufacturers' shipments (thous.of units,saar) [1959:1] (log)

CONTC construct.put in place:total priv \& public 1987\$(mil $\$$, saar) [1964:1] (log)

CONPC construct.put in place:total private 1987\$(mil\$,saar) [1964:1] (log)

CONQC construct.put in place:public construction $87 \$$ (mil $\$$, saar) [1964:1] (log)

CONDO9 construct.contracts: comm'l \& indus.bldgs(mil.sq.ft.floor sp.;sa) [1959:1] (log)

MSMTQ manufacturing \& trade: total (mil of chained 1992 dollars)(sa) [1959:1] (log)

MSMQ manufacturing \& trade:manufacturing;total(mil of chained 1992 dollars)(sa) [1959 (log):1]

MSDQ manufacturing \& trade:mfg; durable goods (mil of chained 1992 dollars)(sa) [1959 (log):1]

MSNQ manufact. \& trade:mfg;nondurable goods (mil of chained 1992 dollars)(sa) [1959:1 (log)] 
WTQ merchant wholesalers: total (mil of chained 1992 dollars)(sa) [1959:1] (log)

WTDQ merchant wholesalers:durable goods total (mil of chained 1992 dollars)(sa) [1959 (log):1]

WTNQ merchant wholesalers:nondurable goods (mil of chained 1992 dollars)(sa) [1959:1] (log)

RTQ retail trade: total (mil of chained 1992 dollars)(sa) [1959:1] (log)

RTDQ retail trade:durable goods total (mil.87\$)(s.a.) [1959:1] (log)

RTNQ retail trade:nondurable goods (mil of 1992 dollars)(sa) [1959:1] (log)

IVMTQ manufacturing \& trade inventories:total (mil of chained 1992)(sa) [1959:1] (log)

IVMFGQ inventories, business, mfg (mil of chained 1992 dollars, sa) [1959:1] (log)

IVMFDQ inventories, business durables (mil of chained 1992 dollars, sa) [1959:1] (log)

IVMFNQ inventories, business, nondurables (mil of chained 1992 dollars, sa) [1959:1] (log)

IVMFNQ inventories, manufacturing \& trade inv:merchant wholesalers (mil of chained 1992 dollars)(s (log) [1959:1]
IVRRQ manufacturing \& trade inv:retail trade (mil of chained 1992 dollars)(sa) [1959: (log)1]

IVSRQ ratio for $\mathrm{mfg} \&$ trade: inventory/sales (chained 1992 dollars, sa) [1959:1]

IVSRMQ ratio for $\mathrm{mfg} \&$ trade: $\mathrm{mfg}$;inventory/sales (87\$)(s.a.) [1959:1]

IVSRWQ ratio for $\mathrm{mfg} \&$ trade: wholesaler;inventory/sales $(87 \$)(\mathrm{s} . \mathrm{a}$.$) [1959:1]$

IVSRRQ ratio for $\mathrm{mfg} \&$ trade:retail trade;inventory/sales(87\$)(s.a.) [1959:1]

PMI purchasing managers' index (sa) [1959:1]

PMP napm production index (percent) [1959:1]

PMNO napm new orders index (percent) [1959:1]

PMDEL napm vendor deliveries index (percent) [1959:1]

PMNV napm inventories index (percent) [1959:1]

PMEMP napm employment index (percent) [1959:1]

PMCP napm commodity prices index (percent) [1959:1]

MOCMQ new orders (net) - consumer goods \& materials, 1992 dollars (bci) [1959:1] (log)

MDOQ new orders, durable goods industries, 1992 dollars (bci) [1959:1] (log)

MSONDQ new orders, nondefense capital goods, in 1992 dollars (bci) [1959:1] (log)

MO mfg new orders: all manufacturing industries, total (mil\$,sa) [1959:1] (log)

MOWU mfg new orders: mfg industries with unfilled orders(mil\$,sa) [1959:1] (log)

MDO mfg new orders: durable goods industries, total (mil\$,sa) [1959:1] (log)

MDUWU mfg new orders:durable goods indust with unfilled orders(mil\$, sa) [1959:1] (log)

MNO mfg new orders: nondurable goods industries, total (mil\$,sa) [1959:1] (log)

MNOU mfg new orders: nondurable gds ind.with unfilled orders(mil\$,sa) [1959:1] (log)

MU mfg unfilled orders: all manufacturing industries, total (mil\$,sa) [1959:1] (log)

MDU mfg unfilled orders: durable goods industries, total (mil\$,sa) [1959:1] (log)

MNU mfg unfilled orders: nondurable goods industries, total (mil\$,sa) [1959:1] (log)

MPCON contracts \& orders for plant \& equipment (bil\$,sa) [1959:1] (log)

MPCONQ contracts \& orders for plant \& equipment in 1992 dollars (bci) [1959:1] (log)

FM1 money stock: m1 (curr,trav.cks, dem dep,other ck'able dep)(bil\$,sa) [1959:1] (log)

FM2 money stock:m2(m1 +o'nite rps, euro\$,g/p\&b/d mmmfs\&sav\&sm time dep(bil\$, [1959:1] (log)

FM3 money stock: $\mathrm{m} 3(\mathrm{~m} 2+\mathrm{lg}$ time dep,term rp's\&inst only mmmfs)(bil\$,sa) [1959:1] (log)

FML money stock:1(m3 + other liquid assets) (bil\$, sa) [1959:1] (log)

FM2DQ money supply - m2 in 1992 dollars (bci) [1959:1] (log)

FMFBA monetary base, adj for reserve requirement changes(mil\$,sa) [1959:1] (log)

FMBASE monetary base, adj for reserve req chgs(frb of st.louis)(bil\$,sa) [1959:1] (log)

FMRRA depository inst reserves:total,adj for reserve req chgs(mil\$,sa) [1959:1] (log)

FMRNBA depository inst reserves:nonborrowed, adj res req chgs(mil\$,sa) [1959:1] (log)

FMRNBC depository inst reserves:nonborrow + ext cr,adj res req cgs(mil\$,sa) [1959:1] (log)

FMFBA monetary base, adj for reserve requirement changes(mil\$,sa) [1959:1] (log)

FCLS loans \& sec @ all coml banks: total (bils,sa) [1973:1] (log)

FCSGV loans \& sec @ all coml banks: U.S.govt securities (bil\$,sa) [1973:1] (log) 
FCLRE loans \& sec @ all coml banks: real estate loans (bil\$,sa) [1973:1] (log)

FCLIN loans \& sec @ all coml banks: loans to individuals (bil\$,sa) [1973:1] (log)

FCLNBF loans \& sec @ all coml banks: loans to nonbank fin inst(bil\$,sa) [1973:1] (log)

FCLNQ commercial \& industrial loans oustanding in 1992 dollars (bci) [1959:1] (log)

FCLBMC wkly rp lg com'l banks:net change com'1 \& indus loans(bil\$,saar) [1959:1]

CCI30M consumer instal.loans: delinquency rate, 30 days \& over, $(\%$, sa) $[1959: 1]$

CCINT net change in consumer instal cr: total (mil\$,sa) [1975:1]

CCINV net change in consumer instal cr: automobile (mil\$,sa) [1975:1]

FSNCOM nyse common stock price index: composite $(12 / 31 / 65=50)[1959: 1](\log )$

FSNIN nyse common stock price index: industrial $(12 / 31 / 65=50)[1966: 1](\log )$

FSNTR nyse common stock price index: transportation $(12 / 31 / 65=50)[1966: 1](\log )$

FSNUT nyse common stock price index: utility $(12 / 31 / 65=50)[1966: 1](\log )$

FSNFI nyse common stock price index: finance $(12 / 31 / 65=50)$ [1966:1] (log)

FSNFI nyse common stock price index: finance $(12 / 31 / 0)$
FSPCOM s\&p's common stock price index: composite $(1941-43=10)[1959: 1](\log )$
FSPIN s\&p's common stock price index: industrials $(1941-43=10)[1959: 1](\log )$
FSPCAP s\&p's common stock price index: capital goods $(1941-43=10)[1959: 1](\log )$

FSPCAP s\&p's common stock price index: capital goods $(1941-43=10)[1959: 1](\log )$

FSPTR s\&p's common stock price index: transportation $(1970=10)[1970: 1](\log )$

FSPUT s\&p's common stock price index: utilities $(1941-43=10)[1959: 1](\log )$

FSPFI s\&p's common stock price index: financial $(1970=10)[1970: 1](\log )$

FSDXP s\&p's composite common stock: dividend yield (\% per annum) [1959:1] (log)

FSPXE s\&p's composite common stock: price-earnings ratio (\%,nsa) [1959:1] (log)

FSNVV3 nyse mkt composition:reptd share vol by size,5000 + shrs, \% [1959:1] (log)

FYFF interest rate: federal funds (effective) (\% per annum,nsa) [1959:1]

FYCP interest rate: commercial paper, 6-month (\% per annum,nsa) [1959:1]

FYGM3 interest rate: U.S.treasury bills, sec mkt,3-mo.(\% per ann,nsa) [1959:1]

FYGM6 interest rate: U.S.treasury bills, sec mkt,6-mo.(\% per ann,nsa) [1959:1]

FYGT1 interest rate: U.S.treasury const maturities, 1-yr.(\% per ann,nsa) [1959:1]

FYGT5 interest rate: U.S.treasury const maturities,5-yr. (\% per ann,nsa) [1959:1]

FYGT10 interest rate: U.S.treasury const maturities, 10-yr.(\% per ann,nsa) [1959:1]

FYBAAC bond yield: moody's baa corporate (\% per annum) [1959:1]

FWAFIT weighted avg foreign interest rate $(\%, \mathrm{sa})[1959: 1]$

FYFHA secondary market yields on fha mortgages (\% per annum) [1959:1]

EXRUS united states; effective exchange rate(merm)(index no.) [1973:1] (log)

EXRGER foreign exchange rate: germany (deutsche mark per U.S.\$) [1973:1] (log)

EXRSW foreign exchange rate: switzerland (swiss franc per U.S.\$) [1973:1] (log)

EXRJAN foreign exchange rate: japan (yen per U.S.\$) [1973:1] (log)

EXRJAN foreign exchange rate: japan (yen per
EXRUK foreign exchange rate: united kingdom (cents per pound) [1973:1] (log)
EXRCAN foreign exchange rate: canada (canadian \$ per U.S.\$) [1973:1] (log)

HHSNTN u. of mich. index of consumer expectations(bcd-83) [1959:1]

F6EDM U.S.mdse exports: [1964:1] $(\log )$

FTMC6 U.S.mdse imports: crude materials \& fuels (mil\$,nsa) [1964:1] (log)

FTMM6 U.S.mdse imports: manufactured goods (mil\$,nsa) [1964:1] (log)

PWFSA producer price index: finished goods $(82=100, \mathrm{sa})[1959: 1](\mathrm{log})$

PWFCSA producer price index:finished consumer goods $(82=100, \mathrm{sa})[1959: 1](\log )$

PWIMSA producer price index:intermed mat.supplies \& components $(82=100$, sa) [1959:1] $(\log )$

PWCMSA producer price index:crude materials $(82=100, \mathrm{sa})[1959: 1](\mathrm{log})$

PWFXSA producer price index: finished goods, excl. foods $(82=100, \mathrm{sa})[1967: 1](\log )$

PW160A producer price index: crude materials less energy $(82=100, \mathrm{sa})[1974: 1](\mathrm{log})$

PW150A producer price index: crude nonfood mat less energy $(82=100$, sa) [1974:1] $(\log )$ 
PW561 producer price index: crude petroleum $(82=100$, nsa) [1959:1] (log)

PWCM producer price index: construction materials $(82=100, \mathrm{nsa})$ [1959:1] (log)

PWXFA producer price index: all commodities ex. farm prod $(82=100, \mathrm{nsa})$ [1959:1] (log)

PSM99Q index of sensitive materials prices $(1990=100)(\mathrm{bci}-99 \mathrm{a})[1959: 1](\mathrm{log})$

PUNEW cpi-u: all items $(82-84=100$, sa) $[1959: 1](\log )$

PU81 cpi-u: food \& beverages $(82-84=100$, sa) [1967:1] $(\log )$

PUH cpi-u: housing $(82-84=100$, sa $)$ [1967:1] $(\log )$

PU83 cpi-u: apparel \& upkeep $(82-84=100$, sa) [1959:1] $(\log )$

PU84 cpi-u: transportation $(82-84=100$, sa) [1959:1] $(\mathrm{log})$

PUC cpi-u: commodities $(82-84=100, \mathrm{sa})[1959: 1](\mathrm{log})$

PUCD cpi-u: durables $(82-84=100$,sa) [1959:1] (log)

PUS cpi-u: services $(82-84=100$, sa) [1959:1] (log)

PUXF cpi-u: all items less food $(82-84=100$, sa) $[1959: 1](\log )$

PUXHS cpi-u: all items less shelter $(82-84=100$, sa) [1959:1] $(\log )$

PUXM cpi-u: all items less midical care $(82-84=100$, sa) [1959:1] $(\log )$

PSCCOM spot market price index:bls \& crb: all commodities $(67=100$, nsa) [1959:1] (log)

PSCFOO spot market price index:bls \& crb: foodstuffs $(67=100, \mathrm{nsa})$ [1959:1] (log)

PSCMAT spot market price index:bls \& crb: raw industrials $(67=100$,nsa) [1959:1] (log)

PZFR prices received by farmers: all farm products $(1977=100, \mathrm{nsa})[1975: 1](\mathrm{log})$

PCGOLD commodities price:gold, london noon fix, avg of daily rate, $\$$ per oz [1975:1] $(\log )$

GMDC pce,impl pr defl:pce $(1987=100)[1959: 1](\mathrm{log})$

GMDCD pce,impl pr defl:pce; durables $(1987=100)$ [1959:1] $(\log )$

GMDCN pce,impl pr defl:pce; nondurables $(1987=100)[1959: 1](\log )$

GMDCS pce,impl pr defl:pce; services $(1987=100)$ [1959:1] $(\mathrm{log})$

GMPYQ personal income (chained) (series \#52) (bil 92\$,saar) [1959:1] (log)

GMYXPQ personal income less transfer payments (chained) (\#51) (bil 92\$,saar) [1959:1] (log)

GMCQ personal consumption expend (chained) - total (bil 92\$, saar) [1959:1] (log)

GMCDQ personal consumption expend (chained) - total durables (bil 92\$, saar) [1959:1] (log)

GMCNQ personal consumption expend (chained) - nondurables (bil 92\$, saar) [1959:1] (log)

GMCSQ personal consumption expend (chained) - services (bil 92\$,saar) [1959:1] (log)

GMCANQ personal cons expend (chained) - new cars (bil 92\$,saar) (log) 


\section{References}

Bates, J.M. and C.W.J. Granger (1969), "The Combination of Forecasts, " Operations Research Quarterly, 20, 451-468.

Brooks, C. (1997), "Linear and Non-linear (Non-)Forecastability of High-frequency Exchange Rates," Journal of Forecasting, 16, 125-145.

Elliott, G., T.J. Rothenberg, and J.H. Stock (1996), "Efficient Tests for an Autoregressive Unit Root," Econometrica, 64, 813-836.

Ghysels, E., C.W.J. Granger, and P.L. Siklos (1996), "Is Seasonal Adjustment a Linear or Nonlinear Data Filtering Process?", Journal of Bueinss and Economic Statistics 14, 374-386.

Granger, C.W.J. (1966), "The Typical Spectral Shape of an Economic Variable," Econometrica, 34, $150-161$.

Granger, C.W.J. (1993), "Strategies for Modelling Nonlinear Time Series Relationships," Economic Record, 60, 233-238.

Granger, C.W.J. and J.-L. Lin (1994), "Forecasting from Non-Linear Models in Practice," Journal of Forecasting, 13, 1-10.

Granger, C.W.J. and P. Newbold (1977), Forecasting Economic Time Series. New York: Academic Press.

Granger, C.W.J. and P. Newbold (1986), Forecasting Economic Time Series, Second Edition. New York: Academic Press.

Granger, C.W.J. and R. Ramanathan (1984), "Improved Methods of Combining Forecasting," Journal of Forecasting, 3, 197-204.

Granger, C.W.J., T. Teräsvirta, and H.M. Anderson (1993), "Modeling Nonlinearity over the Business Cycle," ch. 8 in J.H. Stock and M.W. Watson (eds.), Business Cycles, Indicators, and Forecasting. Chicago: University of Chicago Press for the NBER, 311-327.

Granger, C.W.J. and T. Teräsvirta (1993), Modelling Non-linear Economic Relationships, Oxford: Oxford University Press.

Makridakis, S., A. Anderson, R. Carbonne, R. Fildes, M. Hibon, R. Lewandowski, J. Newton, E. Parzen, and R. Winkler (1982), "The Accuracy of Extrapolation (Time Series) Methods: Results of a Forecasting Competition," Journal of Forecasting, 1, 111-153.

McNees, S.K. (1986), "Forecasting Accuracy of Alternative Techniques: A Comparison of U.S. Macroeconomic Forecasts," Journal of Business and Economic Statistics, 4, 5-24.

McNees, S.K. (1990) "The Role of Judgment in Macroeconomic Forecasting Accuracy," International Journal of Forecasting, 6, 287-299.

Meese, R. and J. Geweke (1984), "A Comparison of Autoregressive univariate Forecasting Procedures for Macroeconomic Time Series," Journal of Business and Economic Statistics, 2, $191-200$ 
Meese, R. and K. Rogoff (1983), "Empirical Exchange Rate Models of the Seventies: Do They Fit Out of Sample?" Journal of International Economics, 14, 3-24.

Stock, J.H. (1996), "VAR, Error Correction and Pretest Forecasts at Long Horizons," Oxford Bulletin of Economics and Statistics 58, no. 4, 685-701; reprinted in A. Banerjee and D.F. Hendry (eds.), The Econometrics of Economic Policy, Oxford: Basil Blackwell, 1997, 115132.

Swanson, N.R. and H. White (1995), "A Model Selection Approach to Assessing the Information in the Term Structure Using Linear Models and Artificial Neural Networks, "Journal of Business and Economic Statistics, 13, 265-275.

Swanson, N.R. and H. White (1997), "A Model Selection Approach to Real-Time Macroeconomic Forecasting Using Linear Models and Artificial Neural Networks, "Review of Economics and Statistics, 79, 540-550.

Teräsvirta, T., D. Tjostheim, and C.W.J. Granger (1994), "Aspects of Modelling Nonlinear Time Series," c. 48 in R. Engle and D. McFadden (eds.), Handbook of Econometrics, v. 4. Amsterdam: Elsevier, 2919-2960.

Weigand, A.S. and N.A. Gershenfeld (1994), Time Series Prediction: Forecasting the Future and Understanding the Past. Addison-Wesley for the Santa Fe Institute: Reading, Massachusetts. 
Table 1

\section{Summary of Forecasting Methods}

\begin{tabular}{|c|c|}
\hline Mnemonic & scription \\
\hline A. Linear & Methods \\
\hline \multicolumn{2}{|l|}{$A R$} \\
\hline $\mathrm{ARFC0} 4$ & levels; constant; 4 lags \\
\hline ARFT0 4 & levels; constant and time trend; 4 lags \\
\hline ARFC14 & differences; constant; 4 lags \\
\hline ARFT14 & differences; constant and time trend; 4 lags \\
\hline ARFCP4 & DF-GLS ${ }_{\tau}^{\mu}$ pretest between ARFC14 and ARFC0 4 \\
\hline ARFTP4 & DF-GLS ${ }^{\top}$ pretest between ARFC14 and ARFT0 4 \\
\hline ARFCOa & levels; constant; AIC lag choice $(0 \leq p \leq 12)$ \\
\hline ARFTOa & levels; constant and time trend; AIC lag choice ( $0 \leq \mathrm{ps} 12$ ) \\
\hline ARFCla & differences; constant; AIC lag choice (0sps12) \\
\hline ARFT1a & differences; constant and time trend; AIC lag choice (0sps12) \\
\hline ARECPa & DF-GLS ${ }_{\tau}^{\mu}$ pretest between ARFCla and ARFCOa \\
\hline ARFTPa & DF-GLS ${ }^{\tau}$ pretest between ARFCla and ARFTOa \\
\hline $\mathrm{ARFCOb}$ & levels; constant; BIC lag choice (0sps12) \\
\hline ARFTOb & levels; constant and time trend; BIC lag choice (0sps12) \\
\hline ARFC1b & differences; constant; BIC lag choice (0sps12) \\
\hline ARFTIb & differences; constant and time trend; BIC lag choice $(0 \leq p \leq 12)$ \\
\hline $\mathrm{ARFCPb}$ & DF-GLS ${ }_{\tau}^{\mu}$ pretest between ARFC1b and ARFCOb \\
\hline ARFTPb & DF-GLS ${ }^{\top}$ pretest between ARFCIb and ARFTOb \\
\hline \multicolumn{2}{|l|}{$E X$} \\
\hline EX1 & Single exponential smoothing \\
\hline EX2 & Double exponential smoothing \\
\hline EXP & DF-GLS ${ }^{\tau}$ pretest between EX1 and EX2 \\
\hline
\end{tabular}

\section{B. Nonlinear Methods}

ANN

AN0 203

AN1203

ANP2 03

AN0213

AN1213

ANP213

AN0 223

AN1223

ANP2 23

ANFOa

ANFla

ANFPa

ANFOb

ANF 1b

ANFPb

LSTAR

LSO 103

LS1103 levels; single layer, 2 hidden units, 3 lags $(p=3)$

differences; single layer, 2 hidden units, 3 lags ( $p=3$ ) DF-GLS ${ }^{\mu}$ pretest between AN0203 and AN1203

levels; two layers, $\mathrm{n}_{1}=2, \mathrm{n}_{2}=1,3$ lags $(\mathrm{p}=3)$

differences; two layers, $\mathrm{n}_{1}=2, \mathrm{n}_{2}=1,3$ lags $(\mathrm{p}=3)$

DF-GLS ${ }^{\mu}$ pretest between ANO213 and AN1213

levels; two layers, $\mathrm{n}_{1}=2, \mathrm{n}_{2}=2,3$ lags $(\mathrm{p}=3)(\mathrm{p}=3)$

differences; two layers, $\mathrm{n}_{1}=2, \mathrm{n}_{2}=2,3$ lags $(\mathrm{p}=3)(\mathrm{p}=3)$

DF-GLS ${ }^{\mu}$ pretest between ANO223 and AN1223

levels; single layer; AIC choice of $\mathrm{n}_{1}, \mathrm{p}\left(1 \leq \mathrm{n}_{1} \leq 4, \mathrm{p}=1,3,6\right)$

differences; single layer; AIC choice of $n_{1}, p\left(1 \leq n_{1} \leq 4, p=1,3,6\right)$ DF-GLS ${ }^{\mu}$ pretest between ANFOa and ANFla

levels; single layer; BIC choice of $n_{1}, p\left(1 \leq n_{1} \leq 4, p=1,3,6\right)$ differences; single layer; BIC choice of $n_{1}, p\left(1 \leq n_{1} \leq 4, p=1,3,6\right)$ DF-GLS ${ }^{\mu}$ pretest between ANFOb and ANF1b

levels; $\xi_{t}=y_{t} ; 3$ lags $(p=3)$

differences; $\xi_{t}=\Delta y_{t} ; 3$ lags $(p=3)$ 
LSP103

LS0063

LS 1063

LSP063

LSFOa

LSFla

LSFPa

LSFOb

LSF1b

$\mathrm{LSFPb}$
DF-GLS ${ }^{\mu}$ pretest between LS0103 and LS1103

levels; $\xi_{\mathrm{t}}=\mathrm{y}_{\mathrm{t}}-\mathrm{y}_{\mathrm{t}-\sigma} ; 3$ lags $(\mathrm{p}=3)$

differences; $\xi_{t}=y_{t}-y_{t-6} ; 3$ lags $(\mathrm{p}=3)$

DF-GLS ${ }^{\mu}$ pretest between LS0063 and LS1063

levels; AIC choice of $\xi_{t}$ and lag length $(p=1,3,6)$

differences; AIC choice of $\xi_{t}$ and lag length $(p=1,3,6)$

DF-GLS ${ }^{\mu}$ pretest between LSFOa and LSFla

levels; BIC choice of $\xi_{t}$ and lag length $(\mathrm{p}=1,3,6)$

differences; BIC choice of $\xi_{t}$ and lag length $(p=1,3,6)$

DF-GLS ${ }^{\mu}$ pretest between LSFOb and LSF1b

\section{No Change \\ NOCHANGE}

\section{Pooling Procedures}

Linear Combination

Clrrro60

Clrrr120

Clrrr999

C2rrro60

C2rrr 120

C2rrr 999

C3rrro60

C3rrr 120

C3rrro99

$\begin{array}{ll}\text { Median } & \\ \text { M1 } & \text { Median, groups A, B \& C } \\ \text { M2 } & \text { Median, group A } \\ \text { M2 } & \text { Median, group B }\end{array}$

\section{PLS}

P0060

P0120

P0999

P1060

P1120

P1999

P2060

P2120

P2999

P3060

P3120

P3999
Avg, groups A, B \& C, MSE wts based on 60 period rolling avg, $\omega=r r r$ Avg, groups A, B \& C, MSE wts based on 120 period rolling avg, $\omega=r r r$ Avg, groups A, B \& C, MSE wts based on recursive avg, $\omega=r r r$ Avg, group A, MSE wts based on 60 period rolling avg, $\omega=r r r$ Avg, group A, MSE wts based on 120 period rolling avg, $\omega=r r r$ Avg, group A, MSE wts based on recursive avg, $\omega=r r r$

Avg, group B, MSE wts based on 60 period rolling avg, $\omega=r r r$

Avg, group B, MSE wts based on 120 period rolling avg, $\omega=r r r$

Avg, group B, MSE wts based on recursive avg, $\omega=r r r$

\section{E. Pooled Over All Groups}

PA060

PA120

PA999
PLS, all primitive fcsts, MSEs computed over 60 period rolling window PLS, all primitive fcsts, MSEs computed over 120 period rolling window PLS, all primitive fcsts, MSEs computed recursively (expanding window) PLS, groups $A, B \& C$, MSEs computed over 60 period rolling window PLS, groups A, B\& C, MSEs computed over 120 period rolling window PLS, groups A, B \& C, MSEs computed recursively (expanding window) PLS, group A, MSEs computed over 60 period rolling window PLS, group A, MSEs computed over 120 period rolling window PLS, group A, MSEs computed recursively (expanding window) PLS, group B, MSEs computed over 60 period rolling window PLS, group B, MSEs computed over 120 period rolling window PLS, group B, MSEs computed recursively (expanding window)

PLS, groups A-D, MSEs computed over 60 period rolling window PLS, groups A-D, MSEs computed over 120 period rolling window PLS, groups A-D, MSEs computed recursively (expanding window) 
Table 2

Mean and percentiles of relative MSEs of various forecasting methods

relative MSE = MSE of method $i / M S E$ of naive model

naive model = ARFC04 (AR (4) in levels with a constant term)

For each forecast, the first row corresponds to one-step ahead forecasts; the second row, to 6-step ahead forecasts; the third row, to 12 -step ahead forecasts.

\begin{tabular}{|c|c|c|c|c|c|c|c|c|}
\hline Method & mean & $2 \frac{\circ}{8}$ & $10 \%$ & $25 \%$ & $50 \%$ & $75^{\circ}$ & $90 \%$ & $98 \frac{\circ}{6}$ \\
\hline \multicolumn{9}{|l|}{$A R$} \\
\hline \multirow{3}{*}{ ARFC0 4} & 1.00 & 1.00 & 1.00 & 1.00 & 1.00 & 1.00 & 1.00 & 1.00 \\
\hline & 1.00 & 1.00 & 1.00 & 1.00 & 1.00 & 1.00 & 1.00 & 1.00 \\
\hline & 1.00 & 1.00 & 1.00 & 1.00 & 1.00 & 1.00 & 1.00 & 1.00 \\
\hline \multirow[t]{3}{*}{ ARFTO 4} & 1.02 & 0.96 & 0.99 & 1.00 & 1.01 & 1.03 & 1.04 & 1.10 \\
\hline & 1.10 & 0.78 & 0.88 & 0.99 & 1.08 & 1.17 & 1.27 & 1.56 \\
\hline & 1.26 & 0.44 & 0.77 & 1.02 & 1.19 & 1.38 & 1.76 & 2.55 \\
\hline \multirow[t]{3}{*}{$\mathrm{ARFC} 14$} & 1.00 & 0.90 & 0.95 & 0.98 & 1.00 & 1.02 & 1.04 & 1.08 \\
\hline & 0.98 & 0.59 & 0.77 & 0.90 & 0.97 & 1.05 & 1.17 & 1.36 \\
\hline & 0.99 & 0.35 & 0.64 & 0.81 & 0.94 & 1.15 & 1.36 & 1.76 \\
\hline \multirow[t]{3}{*}{ ARFT14 } & 1.01 & 0.95 & 0.97 & 0.99 & 1.01 & 1.02 & 1.04 & 1.09 \\
\hline & 1.06 & 0.74 & 0.89 & 0.99 & 1.03 & 1.11 & 1.25 & 1.46 \\
\hline & 1.15 & 0.52 & 0.83 & 0.97 & 1.06 & 1.18 & 1.42 & 1.89 \\
\hline \multirow[t]{3}{*}{ ARFCP4 } & 1.00 & 0.90 & 0.95 & 0.98 & 1.00 & 1.01 & 1.03 & 1.07 \\
\hline & 0.98 & 0.59 & 0.77 & 0.91 & 0.97 & 1.05 & 1.15 & 1.34 \\
\hline & 0.98 & 0.35 & 0.64 & 0.81 & 0.94 & 1.11 & 1.33 & 1.76 \\
\hline \multirow[t]{3}{*}{ ARFTP4 } & 1.00 & 0.90 & 0.95 & 0.98 & 1.00 & 1.02 & 1.04 & 1.07 \\
\hline & 0.98 & 0.59 & 0.77 & 0.91 & 0.97 & 1.06 & 1.16 & 1.34 \\
\hline & 0.99 & 0.35 & 0.64 & 0.81 & 0.95 & 1.14 & 1.36 & 1.76 \\
\hline \multirow[t]{3}{*}{$\mathrm{ARFCOa}$} & 1.02 & 0.83 & 0.95 & 1.00 & 1.02 & 1.04 & 1.07 & 1.14 \\
\hline & 1.00 & 0.61 & 0.86 & 0.99 & 1.01 & 1.06 & 1.13 & 1.24 \\
\hline & 0.98 & 0.63 & 0.87 & 0.98 & 1.00 & 1.02 & 1.08 & 1.18 \\
\hline \multirow[t]{3}{*}{ ARFTOa } & 1.03 & 0.85 & 0.96 & 1.00 & 1.04 & 1.06 & 1.10 & 1.16 \\
\hline & 1.12 & 0.66 & 0.81 & 0.96 & 1.10 & 1.25 & 1.37 & 1.82 \\
\hline & 1.29 & 0.45 & 0.75 & 0.95 & 1.20 & 1.41 & 1.82 & 3.13 \\
\hline \multirow[t]{3}{*}{ ARFCla } & 1.01 & 0.77 & 0.94 & 0.98 & 1.02 & 1.05 & 1.09 & 1.15 \\
\hline & 0.97 & 0.43 & 0.72 & 0.88 & 0.99 & 1.09 & 1.18 & 1.42 \\
\hline & 0.98 & 0.33 & 0.58 & 0.83 & 0.95 & 1.15 & 1.36 & 1.74 \\
\hline \multirow[t]{2}{*}{ ARFTla } & 1.03 & 0.84 & 0.96 & 1.00 & 1.03 & 1.06 & 1.10 & 1.17 \\
\hline & 1.07 & 0.60 & 0.80 & 0.96 & 1.06 & 1.16 & 1.31 & 1.53 \\
\hline
\end{tabular}




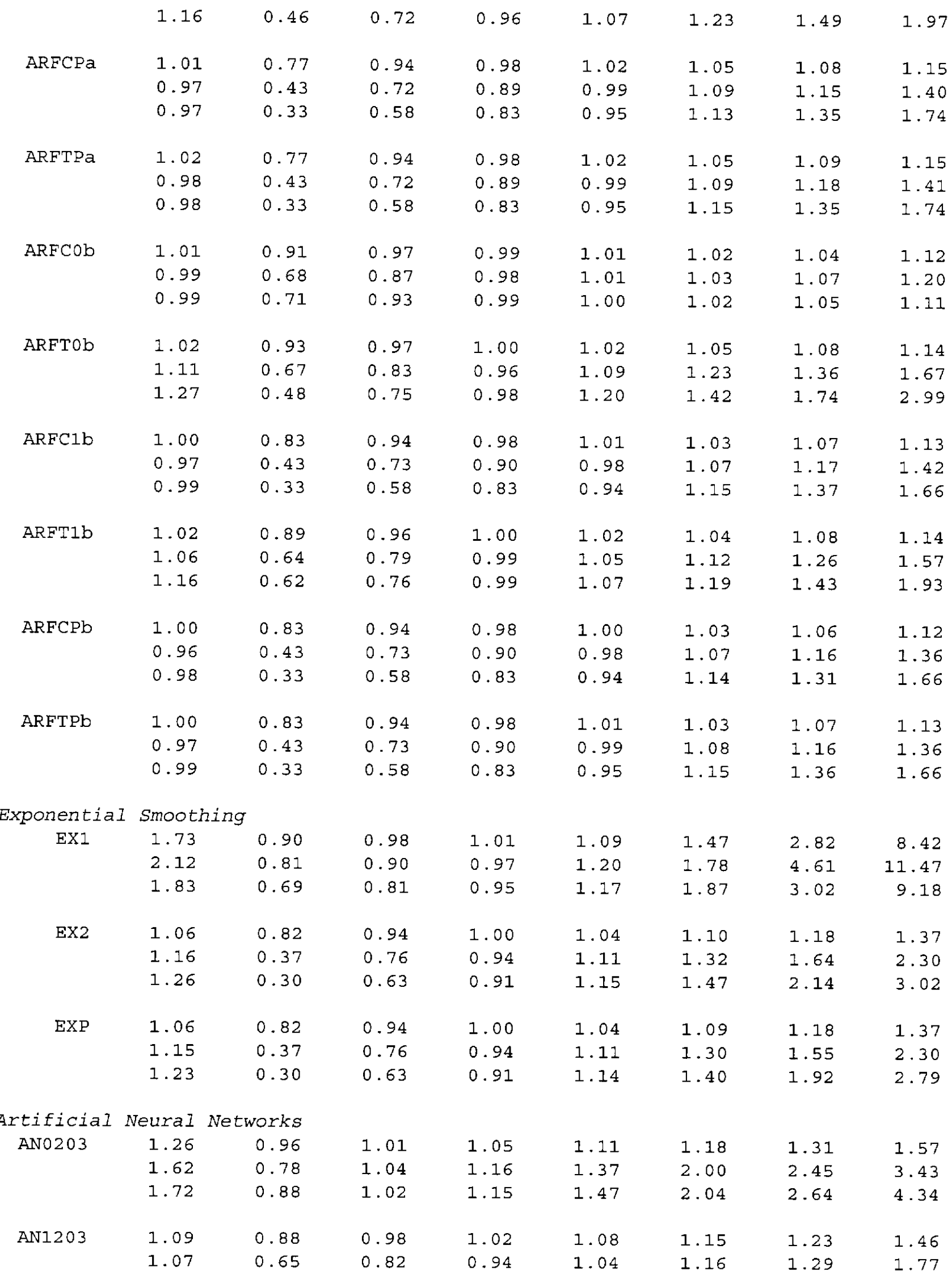




\begin{tabular}{|c|c|c|c|c|c|c|c|c|}
\hline & 1.09 & 0.40 & 0.68 & 0.86 & 1.02 & 1.24 & 1.51 & 2.25 \\
\hline \multirow[t]{3}{*}{ ANP203 } & 1.09 & 0.88 & 0.98 & 1.02 & 1.07 & 1.13 & 1.23 & 1.46 \\
\hline & 1.06 & 0.65 & 0.82 & 0.94 & 1.04 & 1.15 & 1.27 & 1.77 \\
\hline & 1.07 & 0.40 & 0.68 & 0.86 & 1.02 & 1.23 & 1.48 & 2.25 \\
\hline \multirow{3}{*}{ ANO213 } & 1.30 & 0.98 & 1.06 & 1.13 & 1.20 & 1.34 & 1.50 & 2.27 \\
\hline & 2.16 & 0.94 & 1.11 & 1.24 & 1.67 & 2.55 & 3.74 & 6.49 \\
\hline & 2.28 & 0.72 & 1.09 & 1.24 & 1.77 & 2.74 & 4.28 & 7.70 \\
\hline \multirow[t]{3}{*}{ AN1213 } & 1.16 & 0.94 & 1.02 & 1.08 & 1.15 & 1.21 & 1.32 & 1.56 \\
\hline & 1.14 & 0.73 & 0.85 & 0.98 & 1.11 & 1.22 & 1.40 & 1.99 \\
\hline & 1.15 & 0.41 & 0.70 & 0.89 & 1.06 & 1.34 & 1.67 & 2.49 \\
\hline \multirow[t]{3}{*}{ ANP213 } & 1.16 & 0.94 & 1.01 & 1.08 & 1.14 & 1.21 & 1.32 & 1.5 \\
\hline & 1.14 & 0.73 & 0.85 & 0.98 & 1.11 & 1.21 & 1.39 & 2.00 \\
\hline & 1.13 & 0.41 & 0.70 & 0.89 & 1.06 & 1.29 & 1.62 & 2.49 \\
\hline \multirow[t]{3}{*}{ AN0223 } & 1.16 & 0.94 & 1.02 & 1.06 & 1.12 & 1.20 & 1.34 & 1.69 \\
\hline & 1.78 & 0.82 & 1.04 & 1.16 & 1.45 & 2.15 & 2.90 & 4.31 \\
\hline & 1.90 & 0.83 & 1.07 & 1.20 & 1.48 & 2.20 & 3.12 & 6.20 \\
\hline \multirow[t]{3}{*}{ AN1223 } & 1.15 & 0.94 & 1.01 & 1.05 & 1.11 & 1.21 & 1.31 & 1.63 \\
\hline & 1.11 & 0.73 & 0.87 & 0.99 & 1.09 & 1.21 & 1.38 & 1.70 \\
\hline & 1.11 & 0.43 & 0.70 & 0.89 & 1.03 & 1.24 & 1.56 & 2.35 \\
\hline \multirow[t]{3}{*}{ ANP2 23} & 1.15 & 0.94 & 1.01 & 1.05 & 1.11 & 1.21 & 1.32 & 1.6 \\
\hline & 1.11 & 0.73 & 0.87 & 0.99 & 1.10 & 1.21 & 1.34 & 1.70 \\
\hline & 1.10 & 0.43 & 0.70 & 0.90 & 1.03 & 1.24 & 1.50 & 2.35 \\
\hline \multirow[t]{3}{*}{ ANFOa } & 1.27 & 0.85 & 1.05 & 1.14 & 1.22 & 1.37 & 1.55 & 1.86 \\
\hline & 1.99 & 0.90 & 1.13 & 1.34 & 1.68 & 2.32 & 3.16 & 5.64 \\
\hline & 2.13 & 0.76 & 1.12 & 1.33 & 1.73 & 2.44 & 3.76 & 5.43 \\
\hline \multirow[t]{3}{*}{ ANF1a } & 1.28 & 0.96 & 1.06 & 1.14 & 1.23 & 1.38 & 1.51 & 1.92 \\
\hline & 1.23 & 0.67 & 0.84 & 1.08 & 1.19 & 1.33 & 1.58 & 2.27 \\
\hline & 1.22 & 0.39 & 0.68 & 0.95 & 1.14 & 1.48 & 1.77 & 2.59 \\
\hline \multirow[t]{3}{*}{ ANFPa } & 1.28 & 0.97 & 1.06 & 1.14 & 1.23 & 1.38 & 1.51 & 1.88 \\
\hline & 1.23 & 0.67 & 0.84 & 1.08 & 1.19 & 1.33 & 1.56 & 2.06 \\
\hline & 1.20 & 0.39 & 0.68 & 0.95 & 1.14 & 1.40 & 1.72 & 2.59 \\
\hline \multirow[t]{3}{*}{ ANFOb } & 1.16 & 0.90 & 1.01 & 1.06 & 1.11 & 1.21 & 1.36 & 1.72 \\
\hline & 1.83 & 0.82 & 1.08 & 1.23 & 1.50 & 2.15 & 2.78 & 5.03 \\
\hline & 2.08 & 0.75 & 1.05 & 1.26 & 1.63 & 2.38 & 3.75 & 6.49 \\
\hline \multirow[t]{3}{*}{ ANF $1 \mathrm{~b}$} & 1.15 & 0.92 & 0.98 & 1.04 & 1.09 & 1.20 & 1.37 & 1.72 \\
\hline & 1.07 & 0.56 & 0.80 & 0.94 & 1.05 & 1.19 & 1.34 & 1.80 \\
\hline & 1.07 & 0.38 & 0.64 & 0.82 & 1.03 & 1.24 & 1.58 & 2.24 \\
\hline \multirow[t]{3}{*}{$\mathrm{ANFPb}$} & 1.15 & 0.92 & 0.98 & 1.03 & 1.09 & 1.22 & 1.37 & 1.72 \\
\hline & 1.07 & 0.56 & 0.80 & 0.94 & 1.05 & 1.18 & 1.33 & 1.80 \\
\hline & 1.06 & 0.38 & 0.64 & 0.83 & 1.03 & 1.24 & 1.51 & 2.24 \\
\hline
\end{tabular}




\begin{tabular}{|c|c|c|c|c|c|c|c|c|}
\hline \multicolumn{9}{|l|}{$L S T A R$} \\
\hline \multirow[t]{3}{*}{ LS0103 } & 1.07 & 0.91 & 0.98 & 1.01 & 1.05 & 1.10 & 1.17 & 1.31 \\
\hline & 1.24 & 0.80 & 1.00 & 1.06 & 1.15 & 1.34 & 1.72 & 2.00 \\
\hline & 1.34 & 0.56 & 0.92 & 1.07 & 1.19 & 1.45 & 1.95 & 2.89 \\
\hline \multirow{3}{*}{ LS1103 } & 1.06 & 0.90 & 0.95 & 1.00 & 1.04 & 1.09 & 1.16 & 1.38 \\
\hline & 1.04 & 0.69 & 0.82 & 0.93 & 1.02 & 1.11 & 1.26 & 1.60 \\
\hline & 1.05 & 0.40 & 0.67 & 0.84 & 0.98 & 1.20 & 1.44 & 2.21 \\
\hline \multirow[t]{3}{*}{ LSP103 } & 1.05 & 0.90 & 0.96 & 1.00 & 1.04 & 1.08 & 1.15 & 1.33 \\
\hline & 1.03 & 0.69 & 0.82 & 0.93 & 1.02 & 1.11 & 1.22 & 1.60 \\
\hline & 1.04 & 0.40 & 0.67 & 0.85 & 0.98 & 1.18 & 1.41 & 2.21 \\
\hline \multirow[t]{3}{*}{ LS0063 } & 1.04 & 0.93 & 0.97 & 1.00 & 1.03 & 1.07 & 1.12 & 1.25 \\
\hline & 1.09 & 0.75 & 0.92 & 1.00 & 1.06 & 1.14 & 1.28 & 1.52 \\
\hline & 1.10 & 0.74 & 0.92 & 1.01 & 1.06 & 1.16 & 1.26 & 1.61 \\
\hline \multirow[t]{3}{*}{ LS1063 } & 1.03 & 0.85 & 0.95 & 0.99 & 1.02 & 1.06 & 1.11 & 1.27 \\
\hline & 1.01 & 0.52 & 0.72 & 0.91 & 1.00 & 1.12 & 1.24 & 1.46 \\
\hline & 1.04 & 0.34 & 0.60 & 0.83 & 0.96 & 1.20 & 1.45 & 1.99 \\
\hline \multirow[t]{3}{*}{ LSP063 } & 1.03 & 0.85 & 0.95 & 0.99 & 1.02 & 1.06 & 1.11 & 1.24 \\
\hline & 1.00 & 0.52 & 0.72 & 0.91 & 1.00 & 1.11 & 1.22 & 1.42 \\
\hline & 1.03 & 0.34 & 0.60 & 0.84 & 0.96 & 1.17 & 1.45 & 1.99 \\
\hline \multirow[t]{3}{*}{ LSF0a } & 1.13 & 0.92 & 0.98 & 1.04 & 1.08 & 1.18 & 1.33 & 1.68 \\
\hline & 1.42 & 0.77 & 0.96 & 1.11 & 1.29 & 1.57 & 2.10 & 2.99 \\
\hline & 1.47 & 0.73 & 0.92 & 1.12 & 1.34 & 1.70 & 2.13 & 3.27 \\
\hline \multirow[t]{3}{*}{ LSFla } & 1.11 & 0.83 & 0.97 & 1.01 & 1.08 & 1.16 & 1.29 & 1.72 \\
\hline & 1.07 & 0.47 & 0.80 & 0.95 & 1.06 & 1.18 & 1.35 & 1.61 \\
\hline & 1.06 & 0.31 & 0.60 & 0.82 & 1.00 & 1.25 & 1.56 & 2.35 \\
\hline \multirow[t]{3}{*}{ LSFPa } & 1.11 & 0.83 & 0.97 & 1.01 & 1.07 & 1.16 & 1.29 & 1.61 \\
\hline & 1.07 & 0.47 & 0.80 & 0.96 & 1.06 & 1.17 & 1.33 & 1.58 \\
\hline & 1.05 & 0.31 & 0.60 & 0.83 & 1.00 & 1.24 & 1.57 & 2.36 \\
\hline \multirow[t]{3}{*}{ LSFOb } & 1.11 & 0.89 & 0.97 & 1.02 & 1.07 & 1.15 & 1.27 & 1.70 \\
\hline & 1.41 & 0.74 & 0.96 & 1.11 & 1.26 & 1.59 & 1.97 & 3.02 \\
\hline & 1.46 & 0.72 & 0.90 & 1.11 & 1.32 & 1.71 & 2.09 & 3.19 \\
\hline \multirow[t]{3}{*}{ LSFIb } & 1.07 & 0.81 & 0.96 & 1.00 & 1.05 & 1.11 & 1.19 & 1.46 \\
\hline & 1.04 & 0.47 & 0.77 & 0.92 & 1.03 & 1.15 & 1.31 & 1.61 \\
\hline & 1.06 & 0.31 & 0.60 & 0.84 & 0.99 & 1.20 & 1.52 & 2.31 \\
\hline \multirow[t]{3}{*}{ LSFPb } & 1.06 & 0.81 & 0.96 & 1.00 & 1.04 & 1.11 & 1.19 & 1.44 \\
\hline & 1.03 & 0.47 & 0.77 & 0.92 & 1.03 & 1.15 & 1.29 & 1.61 \\
\hline & 1.05 & 0.31 & 0.60 & 0.84 & 0.99 & 1.19 & 1.52 & 2.31 \\
\hline \multicolumn{9}{|l|}{ No Change } \\
\hline \multirow[t]{3}{*}{ NOCHANGE } & 1.76 & 0.89 & 0.99 & 1.04 & 1.12 & 1.49 & 2.82 & 8.42 \\
\hline & 2.14 & 0.81 & 0.90 & 1.00 & 1.22 & 1.78 & 4.61 & 11.47 \\
\hline & 1.83 & 0.69 & 0.82 & 0.97 & 1.21 & 1.77 & 2.93 & 9.18 \\
\hline
\end{tabular}




\begin{tabular}{|c|c|c|c|c|c|c|c|c|}
\hline \multirow{4}{*}{$\begin{array}{l}\text { Combinati } \\
\text { C1000999 }\end{array}$} & fored & \multicolumn{3}{|c|}{ (weighted averages with } & \multicolumn{2}{|c|}{ weights $\left.I / M S E_{i}^{\omega}\right)$} & \multirow[b]{2}{*}{1.01} & \multirow[b]{2}{*}{1.05} \\
\hline & 0.97 & 0.78 & 0.89 & 0.96 & 0.98 & 1.00 & & \\
\hline & 0.91 & 0.42 & 0.69 & 0.87 & 0.95 & 1.00 & 1.06 & 1.12 \\
\hline & 0.89 & 0.26 & 0.55 & 0.79 & 0.91 & 1.02 & 1.10 & 1.34 \\
\hline \multirow[t]{3}{*}{ C2000999 } & 0.98 & 0.81 & 0.91 & 0.96 & 0.99 & 1.01 & 1.02 & 1.06 \\
\hline & 0.92 & 0.46 & 0.68 & 0.88 & 0.96 & 1.01 & 1.08 & 1.15 \\
\hline & 0.90 & 0.37 & 0.57 & 0.81 & 0.93 & 1.05 & 1.16 & 1.33 \\
\hline \multirow[t]{3}{*}{ C3000999 } & 0.98 & 0.79 & 0.89 & 0.96 & 0.99 & 1.01 & 1.04 & 1.09 \\
\hline & 0.94 & 0.45 & 0.77 & 0.88 & 0.96 & 1.03 & 1.10 & 1.21 \\
\hline & 0.91 & 0.28 & 0.60 & 0.82 & 0.92 & 1.05 & 1.16 & 1.39 \\
\hline \multirow{3}{*}{ C1001999 } & 0.97 & 0.76 & 0.90 & 0.96 & 0.98 & 1.00 & 1.01 & 1.05 \\
\hline & 0.91 & 0.47 & 0.72 & 0.88 & 0.95 & 1.00 & 1.05 & 1.11 \\
\hline & 0.89 & 0.37 & 0.58 & 0.80 & 0.92 & 1.03 & 1.12 & 1.35 \\
\hline \multirow[t]{3}{*}{ C2001999 } & 0.98 & 0.82 & 0.91 & 0.97 & 0.99 & 1.01 & 1.02 & 1.05 \\
\hline & 0.93 & 0.48 & 0.71 & 0.90 & 0.96 & 1.01 & 1.08 & 1.15 \\
\hline & 0.91 & 0.43 & 0.57 & 0.81 & 0.94 & 1.07 & 1.15 & 1.40 \\
\hline \multirow[t]{3}{*}{ C3001999 } & 0.98 & 0.79 & 0.89 & 0.96 & 0.99 & 1.01 & 1.04 & 1.08 \\
\hline & 0.93 & 0.50 & 0.72 & 0.88 & 0.96 & 1.02 & 1.08 & 1.17 \\
\hline & 0.91 & 0.33 & 0.59 & 0.81 & 0.92 & 1.05 & 1.16 & 1.40 \\
\hline \multirow[t]{3}{*}{$\mathrm{C} 1001060$} & 0.97 & 0.76 & 0.90 & 0.96 & 0.98 & 1.00 & 1.01 & 1.05 \\
\hline & 0.91 & 0.45 & 0.70 & 0.88 & 0.95 & 1.00 & 1.06 & 1.12 \\
\hline & 0.90 & 0.35 & 0.59 & 0.79 & 0.93 & 1.04 & 1.12 & 1.35 \\
\hline \multirow[t]{3}{*}{ C1001120 } & 0.97 & 0.76 & 0.90 & 0.96 & 0.98 & 1.00 & 1.01 & 1.05 \\
\hline & 0.91 & 0.46 & 0.71 & 0.88 & 0.95 & 0.99 & 1.05 & 1.12 \\
\hline & 0.89 & 0.37 & 0.58 & 0.79 & 0.92 & 1.03 & 1.11 & 1.35 \\
\hline \multirow[t]{3}{*}{ C1005060 } & 0.97 & 0.76 & 0.90 & 0.95 & 0.98 & 1.00 & 1.01 & 1.04 \\
\hline & 0.93 & 0.47 & 0.72 & 0.88 & 0.97 & 1.02 & 1.08 & 1.13 \\
\hline & 0.97 & 0.38 & 0.64 & 0.83 & 0.98 & 1.12 & 1.26 & 1.45 \\
\hline \multirow[t]{3}{*}{$\mathrm{C} 1005120$} & 0.97 & 0.76 & 0.90 & 0.96 & 0.98 & 1.00 & 1.01 & 1.04 \\
\hline & 0.92 & 0.49 & 0.73 & 0.88 & 0.95 & 1.01 & 1.06 & 1.12 \\
\hline & 0.92 & 0.37 & 0.60 & 0.81 & 0.93 & 1.06 & 1.18 & 1.50 \\
\hline \multirow[t]{3}{*}{ C1005999 } & 0.97 & 0.76 & 0.91 & 0.96 & 0.98 & 1.00 & 1.01 & 1.04 \\
\hline & 0.92 & 0.51 & 0.75 & 0.87 & 0.95 & 1.01 & 1.05 & 1.11 \\
\hline & 0.92 & 0.37 & 0.60 & 0.81 & 0.93 & 1.06 & 1.17 & 1.42 \\
\hline \multirow[t]{3}{*}{ C1010060 } & 0.97 & 0.76 & 0.91 & 0.96 & 0.99 & 1.01 & 1.02 & 1.07 \\
\hline & 0.96 & 0.49 & 0.74 & 0.91 & 0.99 & 1.07 & 1.13 & 1.23 \\
\hline & 1.05 & 0.40 & 0.64 & 0.87 & 1.05 & 1.24 & 1.40 & 1.78 \\
\hline \multirow[t]{3}{*}{$\mathrm{C} 1010120$} & 0.97 & 0.76 & 0.91 & 0.96 & 0.99 & 1.01 & 1.02 & 1.06 \\
\hline & 0.93 & 0.51 & 0.72 & 0.89 & 0.97 & 1.02 & 1.08 & 1.19 \\
\hline & 0.96 & 0.37 & 0.60 & 0.83 & 0.97 & 1.08 & 1.23 & 1.77 \\
\hline C1010999 & 0.97 & 0.76 & 0.91 & 0.96 & 0.99 & 1.00 & 1.02 & 1.04 \\
\hline
\end{tabular}




\begin{tabular}{|c|c|c|c|c|c|c|c|c|}
\hline & 0.93 & 0.51 & 0.72 & 0.89 & 0.96 & 1.01 & 1.08 & 1.14 \\
\hline & 0.95 & 0.37 & 0.61 & 0.83 & 0.96 & 1.07 & 1.21 & 1.84 \\
\hline \multirow[t]{3}{*}{$\mathrm{C} 1050060$} & 1.02 & 0.76 & 0.93 & 0.98 & 1.02 & 1.05 & 1.10 & 1.33 \\
\hline & 1.07 & 0.49 & 0.77 & 0.94 & 1.08 & 1.21 & 1.36 & 1.61 \\
\hline & 1.17 & 0.35 & 0.64 & 0.90 & 1.13 & 1.41 & 1.68 & 2.10 \\
\hline \multirow[t]{3}{*}{ C1050120 } & 1.00 & 0.76 & 0.93 & 0.97 & 1.01 & 1.03 & 1.07 & 1.23 \\
\hline & 1.02 & 0.48 & 0.74 & 0.94 & 1.03 & 1.12 & 1.23 & 1.45 \\
\hline & 1.07 & 0.38 & 0.65 & 0.88 & 1.07 & 1.21 & 1.44 & 1.89 \\
\hline \multirow[t]{3}{*}{ C1050999 } & 1.00 & 0.76 & 0.93 & 0.97 & 1.00 & 1.02 & 1.06 & 1.24 \\
\hline & 1.00 & 0.48 & 0.73 & 0.93 & 1.02 & 1.08 & 1.20 & 1.45 \\
\hline & 1.05 & 0.37 & 0.63 & 0.88 & 1.05 & 1.16 & 1.36 & 1.96 \\
\hline \multirow[t]{3}{*}{$\mathrm{C} 1100060$} & 1.04 & 0.78 & 0.94 & 0.99 & 1.03 & 1.07 & 1.12 & 1.38 \\
\hline & 1.10 & 0.51 & 0.80 & 0.95 & 1.10 & 1.25 & 1.41 & 1.63 \\
\hline & 1.19 & 0.37 & 0.67 & 0.90 & 1.13 & 1.45 & 1.74 & 2.14 \\
\hline \multirow[t]{3}{*}{$\mathrm{C} 1100120$} & 1.02 & 0.76 & 0.93 & 0.98 & 1.02 & 1.05 & 1.09 & 1.24 \\
\hline & 1.04 & 0.48 & 0.77 & 0.96 & 1.04 & 1.14 & 1.29 & 1.51 \\
\hline & 1.10 & 0.39 & 0.66 & 0.89 & 1.08 & 1.25 & 1.50 & 1.97 \\
\hline \multirow[t]{3}{*}{ C1100999 } & 1.01 & 0.76 & 0.93 & 0.98 & 1.02 & 1.04 & 1.07 & 1.28 \\
\hline & 1.02 & 0.48 & 0.76 & 0.95 & 1.03 & 1.12 & 1.24 & 1.55 \\
\hline & 1.07 & 0.37 & 0.64 & 0.89 & 1.06 & 1.18 & 1.42 & 2.04 \\
\hline \multirow[t]{3}{*}{ C1500060 } & 1.05 & 0.81 & 0.95 & 1.00 & 1.05 & 1.09 & 1.15 & 1.42 \\
\hline & 1.12 & 0.52 & 0.81 & 0.97 & 1.12 & 1.27 & 1.44 & 1.65 \\
\hline & 1.21 & 0.38 & 0.68 & 0.91 & 1.15 & 1.47 & 1.76 & 2.17 \\
\hline \multirow[t]{3}{*}{ C1500120 } & 1.03 & 0.76 & 0.94 & 0.99 & 1.04 & 1.07 & 1.12 & 1.27 \\
\hline & 1.06 & 0.50 & 0.80 & 0.97 & 1.05 & 1.17 & 1.31 & 1.60 \\
\hline & 1.11 & 0.43 & 0.67 & 0.90 & 1.11 & 1.28 & 1.49 & 2.16 \\
\hline \multirow[t]{3}{*}{ C1500999 } & 1.03 & 0.77 & 0.94 & 0.99 & 1.03 & 1.07 & 1.10 & 1.30 \\
\hline & 1.04 & 0.50 & 0.76 & 0.95 & 1.04 & 1.15 & 1.25 & 1.60 \\
\hline & 1.09 & 0.38 & 0.66 & 0.90 & 1.08 & 1.22 & 1.49 & 2.10 \\
\hline \multirow[t]{3}{*}{$\mathrm{C} 2001060$} & 0.98 & 0.82 & 0.91 & 0.97 & 0.99 & 1.01 & 1.02 & 1.05 \\
\hline & 0.93 & 0.47 & 0.71 & 0.90 & 0.96 & 1.01 & 1.08 & 1.15 \\
\hline & 0.92 & 0.37 & 0.57 & 0.81 & 0.95 & 1.07 & 1.17 & 1.40 \\
\hline \multirow[t]{3}{*}{$\mathrm{C} 2001120$} & 0.98 & 0.82 & 0.91 & 0.97 & 0.99 & 1.01 & 1.02 & 1.05 \\
\hline & 0.93 & 0.48 & 0.71 & 0.90 & 0.96 & 1.01 & 1.08 & 1.15 \\
\hline & 0.91 & 0.43 & 0.57 & 0.80 & 0.94 & 1.05 & 1.15 & 1.40 \\
\hline \multirow[t]{3}{*}{$C 2005060$} & 0.98 & 0.81 & 0.92 & 0.97 & 0.99 & 1.01 & 1.02 & 1.04 \\
\hline & 0.94 & 0.48 & 0.73 & 0.90 & 0.98 & 1.03 & 1.08 & 1.18 \\
\hline & 0.98 & 0.40 & 0.64 & 0.87 & 1.01 & 1.14 & 1.27 & 1.50 \\
\hline \multirow[t]{3}{*}{$\mathrm{C} 2005120$} & 0.98 & 0.82 & 0.91 & 0.97 & 1.00 & 1.01 & 1.02 & 1.04 \\
\hline & 0.93 & 0.51 & 0.72 & 0.89 & 0.97 & 1.01 & 1.07 & 1.16 \\
\hline & 0.93 & 0.43 & 0.60 & 0.82 & 0.96 & 1.06 & 1.14 & 1.52 \\
\hline
\end{tabular}




\begin{tabular}{|c|c|c|c|c|c|c|c|c|}
\hline \multirow[t]{3}{*}{ C2005999 } & 0.98 & 0.82 & 0.91 & 0.97 & 1.00 & 1.01 & 1.02 & 1.04 \\
\hline & 0.93 & 0.52 & 0.72 & 0.89 & 0.97 & 1.02 & 1.07 & 1.16 \\
\hline & 0.93 & 0.42 & 0.61 & 0.82 & 0.96 & 1.06 & 1.16 & 1.52 \\
\hline \multirow[t]{3}{*}{$\mathrm{C} 2010060$} & 0.98 & 0.80 & 0.92 & 0.97 & 1.00 & 1.01 & 1.02 & 1.04 \\
\hline & 0.97 & 0.48 & 0.73 & 0.92 & 1.00 & 1.07 & 1.11 & 1.23 \\
\hline & 1.03 & 0.43 & 0.61 & 0.88 & 1.04 & 1.19 & 1.34 & 1.62 \\
\hline \multirow[t]{3}{*}{ C2010120 } & 0.98 & 0.81 & 0.92 & 0.97 & 1.00 & 1.01 & 1.02 & 1.04 \\
\hline & 0.94 & 0.51 & 0.71 & 0.90 & 0.98 & 1.03 & 1.08 & 1.19 \\
\hline & 0.96 & 0.44 & 0.60 & 0.84 & 0.98 & 1.09 & 1.17 & 1.72 \\
\hline \multirow[t]{3}{*}{ C2010999 } & 0.98 & 0.81 & 0.92 & 0.97 & 1.00 & 1.01 & 1.02 & 1.04 \\
\hline & 0.94 & 0.51 & 0.70 & 0.89 & 0.97 & 1.02 & 1.08 & 1.18 \\
\hline & 0.96 & 0.43 & 0.60 & 0.84 & 0.97 & 1.08 & 1.18 & 1.82 \\
\hline \multirow{3}{*}{$\mathrm{C} 2050060$} & 0.99 & 0.77 & 0.93 & 0.98 & 1.00 & 1.02 & 1.05 & 1.08 \\
\hline & 1.03 & 0.46 & 0.76 & 0.94 & 1.06 & 1.15 & 1.23 & 1.40 \\
\hline & 1.09 & 0.43 & 0.65 & 0.92 & 1.09 & 1.30 & 1.48 & 1.73 \\
\hline \multirow[t]{3}{*}{ C2050120 } & 0.99 & 0.79 & 0.93 & 0.98 & 1.00 & 1.02 & 1.03 & 1.07 \\
\hline & 0.99 & 0.49 & 0.74 & 0.93 & 1.02 & 1.08 & 1.18 & 1.32 \\
\hline & 1.03 & 0.44 & 0.60 & 0.86 & 1.03 & 1.16 & 1.35 & 1.87 \\
\hline \multirow[t]{3}{*}{ C2050999 } & 0.99 & 0.80 & 0.93 & 0.98 & 1.00 & 1.02 & 1.03 & 1.07 \\
\hline & 0.98 & 0.48 & 0.73 & 0.92 & 1.01 & 1.07 & 1.14 & 1.31 \\
\hline & 1.02 & 0.47 & 0.63 & 0.90 & 1.02 & 1.13 & 1.30 & 1.91 \\
\hline \multirow[t]{3}{*}{ C2100060 } & 1.00 & 0.77 & 0.94 & 0.98 & 1.01 & 1.03 & 1.06 & 1.09 \\
\hline & 1.04 & 0.46 & 0.76 & 0.95 & 1.07 & 1.18 & 1.25 & 1.45 \\
\hline & 1.11 & 0.43 & 0.65 & 0.93 & 1.10 & 1.31 & 1.50 & 1.73 \\
\hline \multirow[t]{3}{*}{$\mathrm{C} 2100120$} & 0.99 & 0.80 & 0.93 & 0.98 & 1.01 & 1.02 & 1.04 & 1.09 \\
\hline & 1.00 & 0.49 & 0.74 & 0.94 & 1.03 & 1.11 & 1.20 & 1.34 \\
\hline & 1.04 & 0.44 & 0.62 & 0.88 & 1.04 & 1.18 & 1.36 & 1.89 \\
\hline \multirow[t]{3}{*}{ C2100999 } & 0.99 & 0.80 & 0.94 & 0.98 & 1.01 & 1.02 & 1.04 & 1.08 \\
\hline & 0.99 & 0.48 & 0.74 & 0.92 & 1.02 & 1.08 & 1.16 & 1.32 \\
\hline & 1.04 & 0.47 & 0.64 & 0.91 & 1.03 & 1.16 & 1.34 & 1.91 \\
\hline \multirow[t]{3}{*}{$\mathrm{C} 2500060$} & 1.01 & 0.78 & 0.94 & 0.99 & 1.02 & 1.04 & 1.07 & 1.11 \\
\hline & 1.05 & 0.47 & 0.78 & 0.96 & 1.07 & 1.18 & 1.28 & 1.47 \\
\hline & 1.11 & 0.43 & 0.65 & 0.92 & 1.11 & 1.33 & 1.51 & 1.73 \\
\hline \multirow[t]{3}{*}{$\mathrm{C} 2500120$} & 1.00 & 0.79 & 0.93 & 0.98 & 1.01 & 1.03 & 1.05 & 1.11 \\
\hline & 1.01 & 0.49 & 0.75 & 0.94 & 1.03 & 1.11 & 1.22 & 1.36 \\
\hline & 1.05 & 0.44 & 0.63 & 0.89 & 1.05 & 1.19 & 1.40 & 1.91 \\
\hline \multirow[t]{3}{*}{ C2500999 } & 1.00 & 0.81 & 0.94 & 0.99 & 1.01 & 1.03 & 1.05 & 1.10 \\
\hline & 1.00 & 0.48 & 0.75 & 0.93 & 1.03 & 1.09 & 1.18 & 1.36 \\
\hline & 1.05 & 0.49 & 0.65 & 0.92 & 1.04 & 1.20 & 1.38 & 1.91 \\
\hline C3001060 & 0.98 & 0.79 & 0.89 & 0.96 & 0.99 & 1.01 & 1.04 & 1.08 \\
\hline
\end{tabular}




\begin{tabular}{|c|c|c|c|c|c|c|c|c|}
\hline & 0.93 & 0.48 & 0.71 & 0.87 & 0.96 & 1.02 & 1.09 & 1.18 \\
\hline & 0.91 & 0.33 & 0.62 & 0.81 & 0.93 & 1.06 & 1.17 & 1.35 \\
\hline \multirow[t]{3}{*}{$\mathrm{C} 3001120$} & 0.98 & 0.79 & 0.89 & 0.96 & 0.99 & 1.01 & 1.04 & 1.08 \\
\hline & 0.93 & 0.49 & 0.72 & 0.88 & 0.96 & 1.02 & 1.08 & 1.17 \\
\hline & 0.91 & 0.33 & 0.58 & 0.81 & 0.92 & 1.05 & 1.14 & 1.38 \\
\hline \multirow[t]{3}{*}{ C3005060 } & 0.98 & 0.79 & 0.90 & 0.96 & 0.99 & 1.01 & 1.04 & 1.09 \\
\hline & 0.95 & 0.58 & 0.72 & 0.89 & 0.97 & 1.04 & 1.11 & 1.26 \\
\hline & 0.97 & 0.30 & 0.62 & 0.83 & 0.96 & 1.14 & 1.31 & 1.53 \\
\hline \multirow[t]{3}{*}{ C3005120 } & 0.98 & 0.79 & 0.90 & 0.95 & 0.99 & 1.01 & 1.04 & 1.07 \\
\hline & 0.93 & 0.52 & 0.73 & 0.89 & 0.95 & 1.02 & 1.09 & 1.22 \\
\hline & 0.94 & 0.32 & 0.60 & 0.82 & 0.94 & 1.08 & 1.21 & 1.55 \\
\hline \multirow[t]{3}{*}{ C3005999 } & 0.98 & 0.79 & 0.90 & 0.95 & 0.99 & 1.01 & 1.04 & 1.07 \\
\hline & 0.94 & 0.54 & 0.75 & 0.89 & 0.95 & 1.02 & 1.08 & 1.23 \\
\hline & 0.94 & 0.34 & 0.59 & 0.82 & 0.93 & 1.07 & 1.24 & 1.52 \\
\hline \multirow[t]{3}{*}{ C3010060 } & 0.99 & 0.80 & 0.90 & 0.96 & 0.99 & 1.02 & 1.05 & 1.17 \\
\hline & 0.99 & 0.62 & 0.74 & 0.91 & 1.00 & 1.07 & 1.19 & 1.40 \\
\hline & 1.04 & 0.28 & 0.67 & 0.86 & 1.00 & 1.22 & 1.42 & 1.77 \\
\hline \multirow[t]{3}{*}{$\mathrm{C} 3010120$} & 0.98 & 0.79 & 0.90 & 0.95 & 0.99 & 1.02 & 1.04 & 1.14 \\
\hline & 0.96 & 0.56 & 0.77 & 0.90 & 0.97 & 1.03 & 1.12 & 1.28 \\
\hline & 0.97 & 0.29 & 0.61 & 0.83 & 0.96 & 1.10 & 1.27 & 1.76 \\
\hline \multirow[t]{3}{*}{ C3010999 } & 0.98 & 0.80 & 0.91 & 0.95 & 0.99 & 1.02 & 1.04 & 1.11 \\
\hline & 0.95 & 0.56 & 0.78 & 0.90 & 0.96 & 1.03 & 1.11 & 1.26 \\
\hline & 0.96 & 0.33 & 0.60 & 0.84 & 0.95 & 1.09 & 1.25 & 1.64 \\
\hline \multirow[t]{3}{*}{ C3050060 } & 1.04 & 0.86 & 0.94 & 0.99 & 1.03 & 1.08 & 1.15 & 1.38 \\
\hline & 1.10 & 0.63 & 0.83 & 0.97 & 1.08 & 1.20 & 1.41 & 1.67 \\
\hline & 1.16 & 0.28 & 0.72 & 0.91 & 1.10 & 1.38 & 1.62 & 2.11 \\
\hline \multirow[t]{3}{*}{ C3050120 } & 1.03 & 0.87 & 0.94 & 0.99 & 1.02 & 1.06 & 1.12 & 1.25 \\
\hline & 1.03 & 0.57 & 0.80 & 0.95 & 1.02 & 1.13 & 1.28 & 1.57 \\
\hline & 1.06 & 0.33 & 0.63 & 0.89 & 1.03 & 1.21 & 1.43 & 1.91 \\
\hline \multirow[t]{3}{*}{ C3050999 } & 1.03 & 0.87 & 0.94 & 0.99 & 1.02 & 1.06 & 1.11 & 1.28 \\
\hline & 1.02 & 0.57 & 0.80 & 0.95 & 1.02 & 1.12 & 1.23 & 1.45 \\
\hline & 1.04 & 0.33 & 0.62 & 0.89 & 1.02 & 1.20 & 1.38 & 2.03 \\
\hline \multirow[t]{3}{*}{ C3100060 } & 1.06 & 0.90 & 0.95 & 1.00 & 1.05 & 1.10 & 1.16 & 1.41 \\
\hline & 1.12 & 0.61 & 0.84 & 0.98 & 1.11 & 1.22 & 1.47 & 1.72 \\
\hline & 1.18 & 0.28 & 0.73 & 0.92 & 1.12 & 1.38 & 1.69 & 2.14 \\
\hline \multirow[t]{3}{*}{ C3100120 } & 1.05 & 0.90 & 0.95 & 1.00 & 1.04 & 1.08 & 1.14 & 1.30 \\
\hline & 1.06 & 0.57 & 0.82 & 0.95 & 1.04 & 1.16 & 1.31 & 1.60 \\
\hline & 1.08 & 0.35 & 0.64 & 0.91 & 1.04 & 1.23 & 1.48 & 1.93 \\
\hline \multirow[t]{3}{*}{ C3100999 } & 1.04 & 0.88 & 0.95 & 1.00 & 1.04 & 1.07 & 1.14 & 1.31 \\
\hline & 1.04 & 0.57 & 0.82 & 0.95 & 1.04 & 1.14 & 1.27 & 1.57 \\
\hline & 1.06 & 0.33 & 0.62 & 0.90 & 1.04 & 1.23 & 1.41 & 2.21 \\
\hline
\end{tabular}




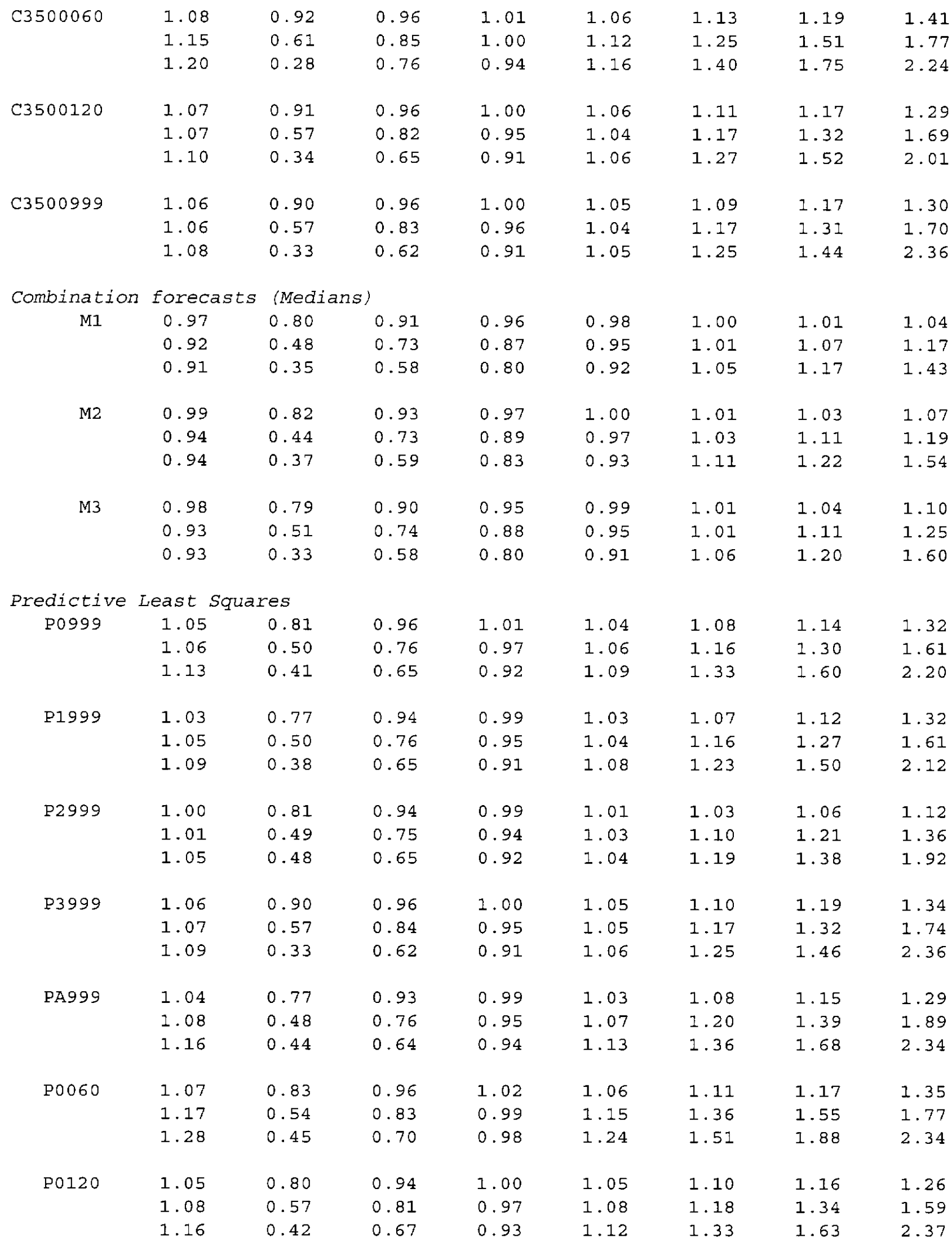




\begin{tabular}{|c|c|c|c|c|c|c|c|c|}
\hline \multirow[t]{3}{*}{ P1060 } & 1.06 & 0.81 & 0.96 & 1.00 & 1.05 & 1.10 & 1.16 & 1.38 \\
\hline & 1.12 & 0.51 & 0.81 & 0.97 & 1.12 & 1.28 & 1.46 & 1.65 \\
\hline & 1.21 & 0.38 & 0.68 & 0.92 & 1.15 & 1.49 & 1.76 & 2.17 \\
\hline \multirow[t]{3}{*}{ P1120 } & 1.04 & 0.77 & 0.95 & 0.99 & 1.04 & 1.08 & 1.13 & 1.27 \\
\hline & 1.06 & 0.50 & 0.80 & 0.97 & 1.07 & 1.17 & 1.32 & 1.60 \\
\hline & 1.12 & 0.44 & 0.67 & 0.90 & 1.11 & 1.29 & 1.51 & 2.19 \\
\hline \multirow[t]{3}{*}{ P2 060} & 1.01 & 0.77 & 0.95 & 0.99 & 1.02 & 1.04 & 1.07 & 1.11 \\
\hline & 1.06 & 0.47 & 0.79 & 0.96 & 1.07 & 1.19 & 1.28 & 1.48 \\
\hline & 1.12 & 0.43 & 0.65 & 0.92 & 1.11 & 1.34 & 1.51 & 1.73 \\
\hline \multirow[t]{3}{*}{ P2120 } & 1.00 & 0.79 & 0.94 & 0.99 & 1.01 & 1.03 & 1.06 & 1.13 \\
\hline & 1.02 & 0.50 & 0.75 & 0.94 & 1.03 & 1.12 & 1.23 & 1.36 \\
\hline & 1.05 & 0.44 & 0.64 & 0.89 & 1.05 & 1.19 & 1.41 & 1.91 \\
\hline \multirow[t]{3}{*}{ P3060 } & 1.08 & 0.92 & 0.96 & 1.01 & 1.06 & 1.13 & 1.20 & 1.42 \\
\hline & 1.15 & 0.61 & 0.85 & 1.01 & 1.12 & 1.28 & 1.52 & 1.78 \\
\hline & 1.20 & 0.28 & 0.77 & 0.94 & 1.16 & 1.42 & 1.75 & 2.25 \\
\hline \multirow[t]{3}{*}{ P3120 } & 1.07 & 0.92 & 0.96 & 1.01 & 1.06 & 1.12 & 1.18 & 1.29 \\
\hline & 1.08 & 0.58 & 0.82 & 0.95 & 1.05 & 1.17 & 1.34 & 1.74 \\
\hline & 1.11 & 0.34 & 0.66 & 0.91 & 1.06 & 1.28 & 1.51 & 2.03 \\
\hline \multirow[t]{3}{*}{ PA060 } & 1.06 & 0.80 & 0.95 & 1.01 & 1.05 & 1.09 & 1.15 & 1.41 \\
\hline & 1.16 & 0.51 & 0.81 & 0.98 & 1.12 & 1.31 & 1.54 & 1.92 \\
\hline & 1.25 & 0.45 & 0.69 & 0.94 & 1.21 & 1.53 & 1.76 & 2.55 \\
\hline \multirow[t]{3}{*}{$\mathrm{PA} 120$} & 1.04 & 0.75 & 0.94 & 1.00 & 1.04 & 1.08 & 1.15 & 1.27 \\
\hline & 1.09 & 0.47 & 0.76 & 0.96 & 1.08 & 1.19 & 1.39 & 1.88 \\
\hline & 1.16 & 0.44 & 0.66 & 0.94 & 1.13 & 1.35 & 1.63 & 2.30 \\
\hline
\end{tabular}


Table 3

Summary of rankings of various methods

Entries are fraction of series for which the indicated method performs in the top $\mathrm{N}$

For each forecast, the first row corresponds to one-step ahead forecasts; the second row, to 6-step ahead forecasts; the third row, to 12 -step ahead forecasts.

\begin{tabular}{|c|c|c|c|c|c|}
\hline Method & $N=1$ & 5 & 10 & 15 & 20 \\
\hline \multicolumn{6}{|l|}{$A R$} \\
\hline \multirow[t]{3}{*}{$\mathrm{ARFCO} 4$} & 0.04 & 0.17 & 0.35 & 0.47 & 0.58 \\
\hline & 0.07 & 0.18 & 0.28 & 0.37 & 0.43 \\
\hline & 0.07 & 0.23 & 0.32 & 0.37 & 0.40 \\
\hline \multirow[t]{3}{*}{ ARFT0 4} & 0.01 & 0.04 & 0.12 & 0.23 & 0.34 \\
\hline & 0.00 & 0.07 & 0.13 & 0.17 & 0.22 \\
\hline & 0.00 & 0.08 & 0.13 & 0.15 & 0.18 \\
\hline \multirow[t]{3}{*}{ ARFC14 } & 0.00 & 0.08 & 0.20 & 0.41 & 0.65 \\
\hline & 0.00 & 0.07 & 0.26 & 0.36 & 0.53 \\
\hline & 0.00 & 0.06 & 0.18 & 0.28 & 0.50 \\
\hline \multirow[t]{3}{*}{ ARFT14 } & 0.00 & 0.03 & 0.09 & 0.18 & 0.29 \\
\hline & 0.00 & 0.02 & 0.05 & 0.09 & 0.16 \\
\hline & 0.01 & 0.03 & 0.06 & 0.12 & 0.16 \\
\hline \multirow[t]{3}{*}{ ARFCP4 } & 0.01 & 0.08 & 0.22 & 0.47 & 0.71 \\
\hline & 0.01 & 0.11 & 0.28 & 0.40 & 0.54 \\
\hline & 0.00 & 0.07 & 0.18 & 0.33 & 0.52 \\
\hline \multirow[t]{3}{*}{ ARFTP4 } & 0.01 & 0.10 & 0.20 & 0.39 & 0.65 \\
\hline & 0.01 & 0.11 & 0.20 & 0.35 & 0.52 \\
\hline & 0.00 & 0.06 & 0.17 & 0.29 & 0.48 \\
\hline \multirow[t]{3}{*}{ ARFCOa } & 0.02 & 0.06 & 0.10 & 0.16 & 0.27 \\
\hline & 0.04 & 0.13 & 0.25 & 0.33 & 0.38 \\
\hline & 0.02 & 0.17 & 0.26 & 0.34 & 0.39 \\
\hline \multirow[t]{3}{*}{ ARFTOa } & 0.01 & 0.01 & 0.07 & 0.10 & 0.18 \\
\hline & 0.05 & 0.07 & 0.10 & 0.13 & 0.17 \\
\hline & 0.04 & 0.08 & 0.10 & 0.13 & 0.16 \\
\hline \multirow[t]{3}{*}{ ARFCla } & 0.00 & 0.08 & 0.13 & 0.22 & 0.33 \\
\hline & 0.01 & 0.07 & 0.19 & 0.33 & 0.47 \\
\hline & 0.01 & 0.09 & 0.24 & 0.32 & 0.47 \\
\hline \multirow[t]{3}{*}{ ARFTla } & 0.00 & 0.03 & 0.05 & 0.11 & 0.17 \\
\hline & 0.00 & 0.03 & 0.05 & 0.08 & 0.13 \\
\hline & 0.00 & 0.03 & 0.07 & 0.13 & 0.17 \\
\hline \multirow[t]{2}{*}{ ARFCPa } & 0.02 & 0.08 & 0.14 & 0.21 & 0.34 \\
\hline & 0.01 & 0.09 & 0.23 & 0.31 & 0.48 \\
\hline
\end{tabular}




$\begin{array}{llllll} & 0.01 & 0.12 & 0.22 & 0.33 & 0.46 \\ \text { ARFTPa } & 0.02 & 0.08 & 0.11 & 0.22 & 0.31 \\ & 0.03 & 0.09 & 0.18 & 0.31 & 0.45 \\ & 0.02 & 0.11 & 0.19 & 0.31 & 0.44 \\ \text { ARFC0b } & 0.02 & 0.08 & 0.15 & 0.31 & 0.46 \\ & 0.02 & 0.11 & 0.24 & 0.31 & 0.40 \\ & 0.03 & 0.19 & 0.29 & 0.34 & 0.39 \\ \text { ARFT0b } & 0.01 & 0.04 & 0.09 & 0.12 & 0.19 \\ & 0.01 & 0.08 & 0.13 & 0.16 & 0.19 \\ & 0.02 & 0.07 & 0.11 & 0.15 & 0.18 \\ \text { ARFC1b } & 0.01 & 0.08 & 0.20 & 0.34 & 0.47 \\ & 0.00 & 0.09 & 0.24 & 0.43 & 0.54 \\ & 0.00 & 0.05 & 0.18 & 0.37 & 0.52 \\ \text { ARFT1b } & 0.00 & 0.05 & 0.08 & 0.15 & 0.23 \\ & 0.01 & 0.02 & 0.05 & 0.09 & 0.15 \\ & 0.00 & 0.02 & 0.05 & 0.08 & 0.12 \\ \text { ARFCPb } & 0.00 & 0.08 & 0.23 & 0.33 & 0.47 \\ & 0.00 & 0.08 & 0.24 & 0.39 & 0.55 \\ & 0.00 & 0.04 & 0.23 & 0.35 & 0.51 \\ \text { ARFTPb } & 0.02 & 0.08 & 0.21 & 0.30 & 0.42 \\ & 0.01 & 0.09 & 0.24 & 0.39 & 0.53 \\ & 0.00 & 0.05 & 0.19 & 0.32 & 0.50\end{array}$

$E X$

EX1

0.05

0.11

0.17

0.23

0.28

0.06

0.22

0.25

0.27

0.17

0.26

0.29

EX2

0.07

0.14

0.19

0.23

0.01

0.10

0.14

0.19

0.26

0.02

0.08

0.16

0.23

EXP

0.09

0.15

0.20

0.24

0.04

0.11

0.15

0.20

0.26

0.02

0.09

0.13

0.17

0.24

ANN

AN0 203

0.00

0.02

0.02

0.03

0.03

0.04

0.05

0.06

0.01

0.03

0.05

0.09

0.07

0.02

0.04

0.06

0.12

AN1203

0.00

0.05

0.08

0.12

0.10

0.00

0.04

0.09

0.12

0.17

0.00

0.02

0.04

0.07

0.15

ANP2 03

0.01
0.01

0.05

0.08

0.14

0.11

0.19 


\begin{tabular}{|c|c|c|c|c|c|}
\hline & 0.00 & 0.04 & 0.09 & 0.12 & 0.15 \\
\hline \multirow[t]{3}{*}{ ANO 213} & 0.00 & 0.00 & 0.01 & 0.01 & 0.01 \\
\hline & 0.00 & 0.00 & 0.02 & 0.02 & 0.04 \\
\hline & 0.01 & 0.02 & 0.04 & 0.05 & 0.07 \\
\hline \multirow[t]{3}{*}{ ANI 213} & 0.00 & 0.00 & 0.01 & 0.01 & 0.02 \\
\hline & 0.00 & 0.01 & 0.02 & 0.05 & 0.07 \\
\hline & 0.00 & 0.01 & 0.04 & 0.05 & 0.08 \\
\hline \multirow[t]{3}{*}{ ANP213 } & 0.00 & 0.00 & 0.01 & 0.02 & 0.03 \\
\hline & 0.00 & 0.00 & 0.03 & 0.07 & 0.07 \\
\hline & 0.00 & 0.01 & 0.03 & 0.05 & 0.08 \\
\hline \multirow[t]{3}{*}{ ANO 223} & 0.00 & 0.01 & 0.03 & 0.04 & 0.04 \\
\hline & 0.00 & 0.02 & 0.03 & 0.03 & 0.03 \\
\hline & 0.00 & 0.02 & 0.04 & 0.07 & 0.08 \\
\hline \multirow[t]{3}{*}{ AN1223 } & 0.00 & 0.01 & 0.01 & 0.03 & 0.06 \\
\hline & 0.00 & 0.01 & 0.03 & 0.05 & 0.07 \\
\hline & 0.00 & 0.02 & 0.06 & 0.11 & 0.15 \\
\hline \multirow[t]{3}{*}{ ANP2 23} & 0.00 & 0.01 & 0.02 & 0.03 & 0.06 \\
\hline & 0.01 & 0.01 & 0.03 & 0.05 & 0.07 \\
\hline & 0.00 & 0.02 & 0.06 & 0.10 & 0.15 \\
\hline \multirow[t]{3}{*}{ ANF0a } & 0.00 & 0.00 & 0.01 & 0.02 & 0.02 \\
\hline & 0.00 & 0.00 & 0.01 & 0.01 & 0.02 \\
\hline & 0.00 & 0.02 & 0.04 & 0.04 & 0.05 \\
\hline \multirow[t]{3}{*}{ ANF1a } & 0.00 & 0.00 & 0.00 & 0.01 & 0.02 \\
\hline & 0.00 & 0.01 & 0.01 & 0.01 & 0.03 \\
\hline & 0.00 & 0.01 & 0.02 & 0.04 & 0.05 \\
\hline \multirow[t]{3}{*}{ ANFPa } & 0.00 & 0.00 & 0.00 & 0.00 & 0.01 \\
\hline & 0.00 & 0.00 & 0.01 & 0.01 & 0.03 \\
\hline & 0.00 & 0.00 & 0.02 & 0.04 & 0.04 \\
\hline \multirow[t]{3}{*}{$\mathrm{ANF} O \mathrm{~b}$} & 0.00 & 0.01 & 0.01 & 0.04 & 0.07 \\
\hline & 0.00 & 0.02 & 0.04 & 0.06 & 0.07 \\
\hline & 0.00 & 0.02 & 0.04 & 0.07 & 0.08 \\
\hline \multirow[t]{3}{*}{$\mathrm{ANF} 1 \mathrm{~b}$} & 0.00 & 0.02 & 0.04 & 0.06 & 0.08 \\
\hline & 0.00 & 0.01 & 0.05 & 0.10 & 0.17 \\
\hline & 0.00 & 0.04 & 0.07 & 0.18 & 0.27 \\
\hline \multirow[t]{3}{*}{ ANFPb } & 0.01 & 0.02 & 0.04 & 0.07 & 0.09 \\
\hline & 0.00 & 0.02 & 0.06 & 0.10 & 0.17 \\
\hline & 0.02 & 0.05 & 0.07 & 0.18 & 0.25 \\
\hline \multicolumn{6}{|c|}{$S T A R$} \\
\hline \multirow[t]{3}{*}{ LSO 0103} & 0.01 & 0.05 & 0.07 & 0.14 & 0.19 \\
\hline & 0.01 & 0.03 & 0.06 & 0.09 & 0.10 \\
\hline & 0.01 & 0.07 & 0.13 & 0.18 & 0.19 \\
\hline
\end{tabular}


LS1103

$\begin{array}{lllll}0.02 & 0.06 & 0.11 & 0.15 & 0.20 \\ 0.01 & 0.02 & 0.07 & 0.12 & 0.27 \\ 0.00 & 0.03 & 0.07 & 0.14 & 0.25\end{array}$

LSP103

0.01

0.06

0.12

0.07

0.15

0.21

0.00

0.02

0.06

0.14

0.27

0.00

0.03

0.14

0.23

LS0063

$$
0.00
$$

0.06

0.13

0.20

0.27

0.03

0.09

0.16

0.20

0.24

0.03

0.08

0.18

0.26

LS1063

$$
0.02
$$

0.09

0.15

0.17

0.24

0.26

0.02

0.08

0.19

0.28

0.35

0.01

0.08

0.14

0.26

0.37

LSP0 63

0.03

0.08

0.14

0.20

0.28

0.02

0.17

0.29

0.39

0.16

0.27

0.37

LSFOa

0.01

0.06

0.09

0.07

0.10

0.04

0.11

0.10

0.01

0.04

0.07

0.10

0.13

LSFla

0.02

0.04

0.07

0.10

0.15

0.00

0.02

0.06

0.19

0.19

0.28

LSFPa

0.00

0.04

0.02

0.08

0.07

0.11

0.11

0.16

0.01

0.14

0.20

0.19

0.28

LSFOb

0.02

0.06

0.08

0.12

0.13

0.02

0.07

0.10

0.12

0.07

0.09

0.13

LSFIb

0.00

0.10

0.13

0.18

0.12

0.18

0.27

0.00

0.09

0.18

0.23

0.33

LSFPb

$$
0.02
$$

0.04

0.10

0.15

0.20

0.12

0.19

0.28

0.02

0.05

0.19

0.24

0.35

No Change NOCHANGE

0.03
0.04
0.04

0.07

0.10

0.17

0.13

0.18

0.13

0.20

0.21

0.21

0.14

0.23

0.25

Combination C1000999

0.39

0.31

0.32
0.68

0.52

0.52
0.83

0.70

0.66
0.93

0.81

0.75 


\begin{tabular}{|c|c|c|c|c|c|}
\hline \multirow[t]{3}{*}{ C2000999 } & 0.03 & 0.26 & 0.53 & 0.74 & 0.87 \\
\hline & 0.08 & 0.23 & 0.44 & 0.67 & 0.85 \\
\hline & 0.07 & 0.18 & 0.37 & 0.60 & 0.74 \\
\hline \multirow[t]{3}{*}{ C3000999 } & 0.05 & 0.28 & 0.44 & 0.57 & 0.73 \\
\hline & 0.07 & 0.23 & 0.36 & 0.46 & 0.58 \\
\hline & 0.10 & 0.23 & 0.37 & 0.49 & 0.61 \\
\hline \multirow{3}{*}{ C1001999 } & 0.03 & 0.38 & 0.67 & 0.86 & 0.96 \\
\hline & 0.01 & 0.24 & 0.54 & 0.74 & 0.88 \\
\hline & 0.01 & 0.18 & 0.44 & 0.65 & 0.81 \\
\hline \multirow[t]{3}{*}{ C2001999 } & 0.00 & 0.17 & 0.46 & 0.71 & 0.87 \\
\hline & 0.00 & 0.14 & 0.35 & 0.58 & 0.81 \\
\hline & 0.02 & 0.14 & 0.33 & 0.53 & 0.70 \\
\hline \multirow[t]{3}{*}{ C3001999 } & 0.03 & 0.27 & 0.50 & 0.62 & 0.75 \\
\hline & 0.02 & 0.24 & 0.34 & 0.51 & 0.65 \\
\hline & 0.00 & 0.18 & 0.36 & 0.50 & 0.67 \\
\hline \multirow[t]{3}{*}{ M1 } & 0.06 & 0.25 & 0.61 & 0.86 & 0.95 \\
\hline & 0.03 & 0.23 & 0.52 & 0.77 & 0.93 \\
\hline & 0.03 & 0.11 & 0.40 & 0.69 & 0.82 \\
\hline \multirow[t]{3}{*}{ M2 } & 0.01 & 0.07 & 0.24 & 0.57 & 0.80 \\
\hline & 0.01 & 0.08 & 0.27 & 0.49 & 0.71 \\
\hline & 0.01 & 0.06 & 0.19 & 0.43 & 0.64 \\
\hline \multirow[t]{3}{*}{ M3 } & 0.07 & 0.33 & 0.52 & 0.67 & 0.75 \\
\hline & 0.09 & 0.26 & 0.43 & 0.58 & 0.73 \\
\hline & 0.02 & 0.20 & 0.37 & 0.55 & 0.70 \\
\hline \multicolumn{6}{|l|}{ PLS } \\
\hline \multirow{3}{*}{ P0999 } & 0.01 & 0.03 & 0.09 & 0.14 & 0.20 \\
\hline & 0.01 & 0.04 & 0.09 & 0.15 & 0.20 \\
\hline & 0.02 & 0.05 & 0.11 & 0.14 & 0.19 \\
\hline \multirow[t]{3}{*}{ P1999 } & 0.00 & 0.04 & 0.08 & 0.13 & 0.23 \\
\hline & 0.00 & 0.03 & 0.11 & 0.18 & 0.22 \\
\hline & 0.00 & 0.05 & 0.11 & 0.19 & 0.23 \\
\hline \multirow[t]{3}{*}{ P2999 } & 0.01 & 0.05 & 0.15 & 0.26 & 0.40 \\
\hline & 0.00 & 0.07 & 0.15 & 0.24 & 0.31 \\
\hline & 0.01 & 0.08 & 0.15 & 0.23 & 0.29 \\
\hline \multirow[t]{3}{*}{ P3999 } & 0.01 & 0.04 & 0.08 & 0.15 & 0.21 \\
\hline & 0.00 & 0.02 & 0.05 & 0.11 & 0.15 \\
\hline & 0.01 & 0.06 & 0.11 & 0.14 & 0.20 \\
\hline \multirow[t]{3}{*}{ PA999 } & 0.00 & 0.04 & 0.12 & 0.17 & 0.26 \\
\hline & 0.00 & 0.06 & 0.11 & 0.19 & 0.26 \\
\hline & 0.00 & 0.02 & 0.08 & 0.11 & 0.17 \\
\hline
\end{tabular}




\section{Table 4}

Rankings of various methods, combined over all series,
for different cost functions: Trimmed forecasts

$$
\text { Cost function }=E\left|e_{t}\right|^{\rho}, e_{t}=\text { forecast error }
$$

For each forecast, the first row corresponds to one-step ahead forecasts; the second row, to 6-step ahead forecasts; the third row, to 12 -step ahead forecasts.

\begin{tabular}{|c|c|c|c|c|c|}
\hline Rank & $\rho=1.00$ & 1.50 & 2.00 & 2.50 & 3.00 \\
\hline \multirow[t]{3}{*}{1} & $\mathrm{C} 1000999$ & C1000999 & $\mathrm{C} 1000999$ & C1001999 & C1001999 \\
\hline & C1000999 & C1000999 & C1000999 & C1000999 & $\mathrm{C} 1000999$ \\
\hline & $\mathrm{C} 1000999$ & $\mathrm{C} 1000999$ & $\mathrm{C} 1000999$ & C1000999 & $\mathrm{C} 1000999$ \\
\hline \multirow[t]{3}{*}{2} & C1001999 & C1001999 & C1001999 & C1000999 & $\mathrm{C} 1000999$ \\
\hline & C1001999 & $\mathrm{C} 1001999$ & C1001999 & C1001999 & $\mathrm{C} 1001999$ \\
\hline & C1001999 & C1001999 & C1001999 & C1001999 & C3000999 \\
\hline \multirow[t]{3}{*}{3} & M1 & M1 & M1 & MI & M1 \\
\hline & M1 & M1 & M1 & M1 & M1 \\
\hline & M1 & M1 & C3000999 & C3000999 & $\mathrm{C} 1001999$ \\
\hline \multirow[t]{3}{*}{4} & M3 & C3001999 & C3001999 & C3001999 & C3001999 \\
\hline & C2000999 & $\mathrm{C} 2000999$ & $\mathrm{C} 2000999$ & C2000999 & $\mathrm{C} 2000999$ \\
\hline & C2000999 & $\mathrm{C} 2000999$ & M1 & C3001999 & C3001999 \\
\hline \multirow[t]{3}{*}{5} & C3001999 & M3 & M3 & C3000999 & c3000999 \\
\hline & $\mathrm{C} 2001999$ & C2001999 & C3001999 & C3001999 & C3001999 \\
\hline & C3001999 & C3001999 & C2000999 & M1 & M1 \\
\hline \multirow[t]{3}{*}{6} & $\mathrm{C} 3000999$ & $C 3000999$ & C3000999 & M3 & $\mathrm{C} 2000999$ \\
\hline & M3 & C3001999 & $\mathrm{C} 2001999$ & C2001999 & $\mathrm{C} 3000999$ \\
\hline & M3 & $\mathrm{C} 3000999$ & C3001999 & $\mathrm{C} 2000999$ & $C 2000999$ \\
\hline \multirow[t]{3}{*}{7} & $\mathrm{C} 2000999$ & $\mathrm{C} 2000999$ & $\mathrm{C} 2000999$ & C2000999 & M3 \\
\hline & M2 & M3 & M3 & C3000999 & C2001999 \\
\hline & C2001999 & M3 & M3 & M3 & M3 \\
\hline \multirow[t]{3}{*}{8} & $\mathrm{C} 2001999$ & $\mathrm{C} 2001999$ & C2001999 & C2001999 & C2001999 \\
\hline & C3001999 & M2 & C3000999 & M3 & M3 \\
\hline & C3000999 & $\mathrm{C} 2001999$ & C2001999 & C2001999 & C2001999 \\
\hline \multirow[t]{3}{*}{9} & M2 & M2 & M2 & M2 & M2 \\
\hline & C3000999 & C3000999 & M2 & M2 & M2 \\
\hline & $\mathrm{M} 2$ & M2 & M2 & M2 & M2 \\
\hline \multirow[t]{3}{*}{10} & ARFCP4 & ARFCP4 & ARFCP 4 & ARFCP 4 & ARFCP4 \\
\hline & $\mathrm{ARFCPb}$ & $\mathrm{ARFCPb}$ & ARFCPb & $\mathrm{ARECPb}$ & ARFCPb \\
\hline & ARFCPa & $\mathrm{ARFCPa}$ & ARFCPa & $\mathrm{ARFCPa}$ & ARFCla \\
\hline
\end{tabular}




\begin{tabular}{|c|c|c|c|c|c|}
\hline \multirow[t]{3}{*}{11} & $\mathrm{ARFC14}$ & ARFTP4 & ARFTP4 & ARFTP4 & ARFTP4 \\
\hline & ARFCPa & $\mathrm{ARFTPb}$ & $\mathrm{ARFTPb}$ & $\mathrm{ARFTPb}$ & ARFTPb \\
\hline & ARFC1a & ARFCla & ARFCla & ARFCla & ARFCPa \\
\hline \multirow[t]{3}{*}{12} & ARFTP4 & ARFCl4 & ARFC14 & $\mathrm{ARFC} 14$ & ARFC 04 \\
\hline & $\mathrm{ARFTPb}$ & ARFClb & ARFC1b & ARFC1b & ARFCIb \\
\hline & ARFTPa & ARFTPa & ARFTPa & ARFTPa & ARFTPa \\
\hline \multirow[t]{3}{*}{13} & P2999 & $\mathrm{ARFCO} 4$ & ARFC0 4 & $\mathrm{ARFCO} 4$ & ARFC14 \\
\hline & ARFCla & $\mathrm{ARFCPa}$ & ARFCPa & ARFCPa & ARFCP 4 \\
\hline & $\mathrm{ARFCPb}$ & $\mathrm{ARFCPb}$ & ARFCPb & $\mathrm{ARFCPb}$ & $\mathrm{ARFCPb}$ \\
\hline \multirow{3}{*}{14} & $\mathrm{ARFCPb}$ & P2999 & P2999 & P2999 & P2999 \\
\hline & ARFC1b & ARFCla & ARFCla & ARFCla & ARFCPa \\
\hline & $\mathrm{ARFTPb}$ & ARFClb & ARFCIb & ARFC1b & ARFCIb \\
\hline \multirow[t]{3}{*}{15} & $\mathrm{ARFC1b}$ & $\mathrm{ARFCPb}$ & $\mathrm{ARFCPb}$ & $\mathrm{ARFCPb}$ & $\mathrm{ARFCPb}$ \\
\hline & ARFTPa & ARFTPa & ARFTPa & ARFTPa & ARFCla \\
\hline & ARFC1b & ARFTPb & $\mathrm{ARFTPb}$ & $\mathrm{ARFTPb}$ & ARFTPb \\
\hline \multirow[t]{3}{*}{16} & $\mathrm{ARFTPb}$ & ARFTPb & $\mathrm{ARFTPb}$ & ARFCOb & ARFCOb \\
\hline & ARFCP4 & ARFCP4 & ARFCP4 & $\mathrm{ARFCP} 4$ & ARFTPa \\
\hline & ARFCP4 & ARFCP4 & ARFCP4 & ARFCP4 & ARFCP4 \\
\hline \multirow[t]{3}{*}{17} & $\mathrm{ARFCO} 4$ & ARFC1b & ARFCIb & $\mathrm{ARFTPb}$ & ARFTPb \\
\hline & ARFC14 & ARFCl 4 & ARFC14 & ARFC14 & ARFC14 \\
\hline & ARFC14 & ARFC14 & ARFC14 & ARFC14 & ARFC14 \\
\hline \multirow[t]{3}{*}{18} & $\mathrm{ARFCOb}$ & $\mathrm{ARFCOb}$ & ARFCOb & ARFCIb & ARFCIb \\
\hline & ARFTP4 & ARFTP4 & ARFTP4 & ARFTP4 & ARFTP4 \\
\hline & ARFTP4 & ARFTP4 & ARFTP4 & ARFTP4 & ARFTP4 \\
\hline \multirow[t]{3}{*}{19} & ARFCPa & ARFT14 & ARFT14 & ARFT14 & ARFTO 4 \\
\hline & LSP0 63 & LSP063 & LSP0 63 & ARFCOb & LSP0 63 \\
\hline & LSP0 63 & LSP063 & LSP0 63 & LSP0 63 & LSP0 63 \\
\hline \multirow[t]{3}{*}{20} & ARFCla & $\mathrm{ARFCPa}$ & ARFCPa & ARFT0 4 & ARFT14 \\
\hline & LS1063 & $\mathrm{ARFCOb}$ & ARFCOb & LSP0 63 & $A R F C O b$ \\
\hline & LSFPb & LS1063 & LS1063 & LS1063 & LS 1063 \\
\hline \multirow[t]{3}{*}{21} & ARFTPa & ARFC1a & ARFT04 & ARFCOa & $\mathrm{ARFCO}$ \\
\hline & $\mathrm{ARFCOb}$ & LS1063 & LS1063 & LS1063 & P2999 \\
\hline & LS1063 & LSFPb & LSFPb & LSF1b & LSF1b \\
\hline \multirow[t]{3}{*}{22} & ARFT14 & ARFTPa & ARFCla & ARFCPa & ARFTOb \\
\hline & P2999 & P2999 & P2999 & P2999 & ARFCO 4 \\
\hline & LSFIb & LSF1b & LSFIb & LSFPb & LSFPb \\
\hline \multirow[t]{3}{*}{23} & P1999 & $\mathrm{ARFCOa}$ & ARFCOa & ARFCla & ARFT1b \\
\hline & ARFCOa & $\mathrm{ARFCOa}$ & ARFCOa & $\mathrm{ARFCO} 4$ & LS1063 \\
\hline & LSFPa & LSFPa & LSFPa & LSEPa & LSFPa \\
\hline \multirow[t]{2}{*}{24} & ARFCOa & ARFT1b & ARFTPa & ARFT1b & $\mathrm{ARFCPa}$ \\
\hline & LSFPb & LSFPb & $\mathrm{ARFCO} 4$ & ARFCOa & ARFCOa \\
\hline
\end{tabular}




\begin{tabular}{|c|c|c|c|c|c|}
\hline & LSF1a & LSF1a & LSFla & LSFla & LSFIa \\
\hline \multirow[t]{3}{*}{25} & LSP063 & ARFT0 4 & ARFTIb & ARFTPa & ARFCla \\
\hline & LSFIb & LSFIb & LSFPb & LSFPb & LSP103 \\
\hline & $\mathrm{ARFCOa}$ & $\mathrm{ARFCOa}$ & ARFCOa & ARFCOa & ARFCOa \\
\hline \multirow[t]{3}{*}{26} & PA999 & LSP0 63 & ARFTOb & ARFTOb & ARFTPa \\
\hline & P1999 & $\mathrm{ARFCO} 4$ & LSF1b & LSFIb & ARFT14 \\
\hline & ANFPb & ANFPb & ANFPb & ANFPb & LSP103 \\
\hline \multirow[t]{3}{*}{27} & LS1063 & LS1063 & LSP0 63 & LSP0 63 & ARFT0a \\
\hline & $\mathrm{ARFCO} 4$ & LSP103 & LSP103 & LSP103 & LSFPb \\
\hline & ANF1b & ANF1b & ANF1b & LSP103 & LS1103 \\
\hline \multirow[t]{3}{*}{28} & ARFTIb & P1999 & LS1063 & ARFTla & LSP0 63 \\
\hline & LSFPa & P1999 & LS1103 & LS1103 & LSF $1 b$ \\
\hline & LSP103 & LSP103 & LSP103 & ANF1b & $\mathrm{ANFPb}$ \\
\hline \multirow[t]{3}{*}{29} & ARFT04 & ARFTOb & ARFTla & ARFTOa & ARFTla \\
\hline & LSP103 & LS1103 & P1999 & ARFTlb & ARFT1b \\
\hline & $\mathrm{ARFCOb}$ & $\mathrm{ARFCOb}$ & $\mathrm{ARFCOb}$ & LS1103 & P2999 \\
\hline \multirow[t]{3}{*}{30} & ARFT1a & ARFT1a & P1999 & LS1063 & LS1063 \\
\hline & LSFIa & LSFPa & ARFT1b & ARFT14 & LS1103 \\
\hline & LS1103 & LS1103 & LS1103 & $\mathrm{ARFCOb}$ & $\mathrm{ARFCOb}$ \\
\hline \multirow[t]{3}{*}{31} & ARFTOb & PA999 & ARFTOa & LS0063 & LS0063 \\
\hline & LS1103 & LSFla & ARFT14 & P1999 & ARFTIa \\
\hline & P2999 & ANP203 & ANP2 03 & P2999 & P3999 \\
\hline \multirow[t]{3}{*}{32} & LSP103 & LS0063 & LS0063 & P1999 & EXP \\
\hline & P0999 & P0999 & LSF1a & ARFTla & ANP2 03 \\
\hline & ANP2 03 & P2999 & P2999 & ANP203 & ANP2 03 \\
\hline \multirow[t]{3}{*}{33} & LS0 063 & P0999 & PA999 & EXP & EX2 \\
\hline & P3999 & ARFT1b & LSFPa & ANP203 & P1999 \\
\hline & AN1203 & AN1203 & P3999 & P3999 & ANF $1 \mathrm{~b}$ \\
\hline \multirow[t]{3}{*}{34} & P0999 & ARFT0a & P0999 & P0999 & P1999 \\
\hline & ANFPb & P3999 & P0999 & P0999 & AN1203 \\
\hline & P3999 & P3999 & AN1 203 & AN1203 & AN1 203 \\
\hline \multirow[t]{3}{*}{35} & LS1103 & LSP103 & EXP & EX2 & P0999 \\
\hline & ANF1b & ANFPb & ANP203 & AN1203 & ARFT0 4 \\
\hline & P1999 & P1999 & P1999 & P1999 & P1999 \\
\hline \multirow[t]{3}{*}{36} & LSFPb & LS1103 & LSP103 & LSP103 & LS0103 \\
\hline & ARFT1b & ANF1b & ARFTla & LSF1a & P0999 \\
\hline & $\mathrm{ARFCO} 4$ & $\mathrm{ARFCO} 4$ & $\mathrm{ARFCO} 4$ & $\mathrm{ARFC} 04$ & ANP2 23 \\
\hline \multirow[t]{3}{*}{37} & LSF1b & LSFPb & $\mathrm{EX} 2$ & LS0103 & LSP 103 \\
\hline & PA999 & ARFTla & P3999 & LSFPa & LSFla \\
\hline & ANP2 23 & ANP223 & ANP223 & ANP223 & ARFCO 4 \\
\hline
\end{tabular}




\begin{tabular}{|c|c|c|c|c|c|}
\hline \multirow{3}{*}{38} & ARFTOa & EXP & LS1103 & LS1103 & LS1103 \\
\hline & ARFT1a & ANP203 & AN1203 & P3999 & ARFTOb \\
\hline & AN1223 & AN1223 & AN1223 & AN1223 & AN1223 \\
\hline \multirow[t]{3}{*}{39} & P3999 & LSF1b & LSFPb & PA999 & P3999 \\
\hline & ANP2 03 & ARFT14 & ANF1b & ANF1b & LSFPa \\
\hline & ANP213 & ANP2 13 & ANP213 & PA999 & ARFTIa \\
\hline \multirow[t]{3}{*}{40} & EXP & $\mathrm{EX} 2$ & LSO103 & $\mathrm{LSFPb}$ & LSFPb \\
\hline & ARFT14 & AN1203 & ANFPb & ANFPb & LS0063 \\
\hline & AN1213 & P0999 & P0999 & ARFTla & PA999 \\
\hline \multirow[t]{3}{*}{41} & $\mathrm{EX} 2$ & P3999 & P3999 & P3999 & LSFIb \\
\hline & AN1203 & PA999 & PA999 & LS0063 & ARFTOa \\
\hline & P0999 & AN1213 & PA999 & P0999 & P0999 \\
\hline \multirow[t]{3}{*}{42} & LSFPa & LS0103 & LSF1b & LSEIb & PA999 \\
\hline & LS0063 & LSO0063 & LS0063 & ARFT0 4 & P3999 \\
\hline & PA999 & PA999 & ARFTla & ANP2 13 & EXP \\
\hline \multirow[t]{3}{*}{43} & LSO103 & ANP203 & ANP2 03 & ANP203 & ANP203 \\
\hline & ANP2 23 & ANP2 23 & ARFT04 & PA999 & ANF $1 \mathrm{~b}$ \\
\hline & LS0063 & ARFTla & AN1213 & AN1213 & ANP2 13 \\
\hline \multirow[t]{3}{*}{44} & LSFla & AN1203 & AN1203 & AN1203 & AN1203 \\
\hline & EXP & AN1223 & ANP2 23 & ARFTOb & $\mathrm{ANFPb}$ \\
\hline & ARFT1a & LS0063 & $\operatorname{EXP}$ & $\mathrm{EXP}$ & $\mathrm{EX} 2$ \\
\hline \multirow[t]{3}{*}{45} & ANP203 & LSFPa & LSFOb & LSFOb & LSFOb \\
\hline & $A N 1223$ & EXP & AN1223 & ARFTOa & PA999 \\
\hline & ANFPa & $\mathrm{ANFPa}$ & ARFTIb & EX2 & AN1213 \\
\hline \multirow[t]{3}{*}{46} & $\mathrm{AN} 1203$ & LSF1a & LSFPa & LSFPa & LSFPa \\
\hline & $\mathrm{EX} 2$ & ARFT0 4 & ARFTOb & ANP2 23 & EXP \\
\hline & ANF1a & ARFTIb & ANFPa & ARFTlb & ARFT1b \\
\hline \multirow[t]{3}{*}{47} & LSFOb & LSFOb & LSFIa & LSF1a & LSFIa \\
\hline & ANP2 13 & ARFTOb & EXP & $\operatorname{EXP}$ & $\mathrm{EX} 2$ \\
\hline & ARFTIb & EXP & ARFT14 & ARFT14 & ARFT14 \\
\hline \multirow[t]{3}{*}{48} & LSFOa & LSFOa & LSFOa & LSFOa & LSF0a \\
\hline & AN1213 & $\mathrm{EX} 2$ & ARFT0a & AN1223 & ANP2 23 \\
\hline & EXP & ARFT14 & LS0063 & ANFPa & ANFPa \\
\hline \multirow[t]{3}{*}{49} & ANFIb & ANF1b & $\mathrm{AN} 1223$ & ANO 223 & ANP213 \\
\hline & ARFTOb & ANP2 13 & $\mathrm{EX} 2$ & $\mathrm{EX} 2$ & AN1223 \\
\hline & ARFT14 & ANFla & ANF1a & ANFla & ANF1a \\
\hline \multirow[t]{3}{*}{50} & ANFPb & $\mathrm{ANFPb}$ & ANP2 23 & ANP2 13 & AN1213 \\
\hline & ARFT0 4 & ARFT0a & ANP213 & AN1213 & AN1213 \\
\hline & $\mathrm{EX} 2$ & $\mathrm{EX} 2$ & $\mathrm{EX} 2$ & LS0063 & LS0063 \\
\hline \multirow[t]{2}{*}{51} & ANP2 23 & AN1223 & ANF1b & AN1213 & ANO 223 \\
\hline & ARFTOa & AN1213 & AN1213 & ANP2 13 & ANP2 13 \\
\hline
\end{tabular}


AN1223

AN1223

ANFOb

ANFOb

ANO 223

ANP2 23

ANP2 23

ANF1a

ANFIa

ANF1a

ANF1a

ANF1a

ARFTOa

ARFT0 4

ARFTO 4

ARFT0 4

ARFT0 4

54

ANP213

ANP2 13

LS0103

LS0103

LS0103

LS0103

55

AN1213
LSFOb
LSFOb

AN1213

LSFOb

ISFOb

56

ANO223

ANO 223

ISFOa

LSFOa

LSFOa

LSEOa

57

ANO 203

AN02 03

AN0 203

ANO203

AN0 203

58

ANFIa

ANO2 23

ANFla

ANO2 23

ANO223

AN0223

59

ANFPa

ANFOb

NOCHANGE

ANFPa

ANFOb

NOCHANGE

60

ANFOa

ANFOa

ANEOa

ANFOa

EX1

EX1

61

$$
\begin{array}{r}
\text { AN0213 } \\
\text { EX1 } \\
\text { ANFOb }
\end{array}
$$

62

EX1

ANO213

ANFOa

NOCHANG

ANFOa

63

NOCHANGE
NOCHANGE

ANO213

NOCHANGE

AN0213

ANO213
ANFOb

LS0103

LS0103

ANP213

LSFOb

LSFOb

AN1213

LSFOa

LSFOa

ANFOa

AN0203

AN0203

ANFla

ANO223

ANFOb

ANFPa

LSO103

ANF $1 b$

LSFOb

LSFOb

ANFPb

LSFOa

LSFOa

ANFOa

ANO 203

ANO 203

ANFla

ANO 223

ANO223

ANFPa

ANFOb

NOCHANGE

ANFPa

ANFOb

NOCHANGE

ANO203

ANFOa

EX1

ANO213

EX1

$\mathrm{ANFOb}$

AN0213

EX1

EX1

AN0203

NOCHANGE

ANFOb

EX1

NOCHANGE

ANFOa

EX1

ANFOa

ANFOa

NOCHANGE

AN0213

AN0 213
NOCHANGE
ANO 213
ANO213
AN0203

AN0203

ANF1a

AN0 223

AN0223

AN0 213

$\mathrm{ANFOb}$

NOCHANGE

ANFPa

EX1

EX1

EXI

NOCHANGE ANFOb

ANFOa

ANFOa 


\section{Rankings of various methods, combined over all series, for different cost functions: Untrimmed forecasts}

$$
\text { Cost function }=E\left|e_{t}\right|^{P}, e_{t} \text { =forecast error }
$$

For each forecast, the first row corresponds to one-step ahead forecasts; the second row, to 6-step ahead forecasts; the third row, to 12 -step ahead forecasts.

\begin{tabular}{|c|c|c|c|c|c|}
\hline Rank & $\rho=1.00$ & 1.50 & 2.00 & 2.50 & 3.00 \\
\hline \multirow[t]{3}{*}{1} & M1 & M1 & M1 & M1 & $\mathrm{MI}$ \\
\hline & M1 & M1 & M1 & M1 & M1 \\
\hline & $\mathrm{C} 2000999$ & $C 2000999$ & C2000999 & M1 & M1 \\
\hline \multirow[t]{3}{*}{2} & M3 & M3 & C2000999 & $\mathrm{C} 2000999$ & C2000999 \\
\hline & $\mathrm{C} 2000999$ & $\mathrm{C} 2000999$ & $\mathrm{C} 2000999$ & $\mathrm{C} 2000999$ & $\mathrm{C} 2000999$ \\
\hline & M1 & M1 & M1 & C2000999 & $C 2000999$ \\
\hline \multirow[t]{3}{*}{3} & C2000999 & $\mathrm{C} 2000999$ & C2001999 & C2001999 & $\mathrm{C} 2001999$ \\
\hline & C2001999 & $\mathrm{C} 2001999$ & M3 & M3 & M3 \\
\hline & C2001999 & C2001999 & C2001999 & C2001999 & C2001999 \\
\hline \multirow[t]{3}{*}{4} & C2001999 & C2001999 & M3 & M3 & M3 \\
\hline & M3 & M3 & $\mathrm{C} 2001999$ & $\mathrm{C} 2001999$ & $\mathrm{C} 2001999$ \\
\hline & M3 & M3 & M3 & M2 & M2 \\
\hline \multirow[t]{3}{*}{5} & M2 & M2 & M2 & M2 & M2 \\
\hline & M2 & M2 & M2 & M2 & M2 \\
\hline & M2 & M2 & M2 & M3 & M3 \\
\hline \multirow[t]{3}{*}{6} & ARFCP4 & ARFCP4 & ARFCP4 & ARFCP4 & ARFCP4 \\
\hline & $\mathrm{ARFCPb}$ & $\mathrm{ARFCPb}$ & $\mathrm{ARFCPb}$ & $\mathrm{ARFCPb}$ & ARFCPb \\
\hline & $\mathrm{ARFCPa}$ & ARFCPa & ARFCPa & $\mathrm{ARFCPa}$ & ARFCla \\
\hline \multirow[t]{3}{*}{7} & ARFC14 & ARFTP4 & ARFTP4 & ARFTP4 & ARFTP4 \\
\hline & ARFCPa & ARFTPb & ARFTPb & $\mathrm{ARFTPb}$ & ARFTPb \\
\hline & ARFC1a & ARFCla & ARFCla & ARFCla & ARFCPa \\
\hline \multirow[t]{3}{*}{8} & ARFTP4 & ARFC14 & $\mathrm{ARFC14}$ & ARFCl 4 & ARFCO 4 \\
\hline & ARFTPb & ARFC1b & ARFC $1 b$ & ARFCIb & ARFClb \\
\hline & ARFTPa & ARFTPa & ARFTPa & ARFTPa & ARFTPa \\
\hline \multirow[t]{3}{*}{9} & P2999 & $\mathrm{ARFCO} 4$ & $\mathrm{ARFCO} 4$ & ARFC 04 & ARFC14 \\
\hline & ARFCla & ARFCPa & ARFCPa & ARFCPa & ARFCPa \\
\hline & $\mathrm{ARFCPb}$ & $\mathrm{ARFCPb}$ & $\mathrm{ARFCPb}$ & ARFCPb & ARFCPb \\
\hline \multirow[t]{3}{*}{10} & ARFCPb & P2999 & P2999 & P2999 & P2999 \\
\hline & ARFCIb & ARFCla & ARFCla & ARFCla & ARFCla \\
\hline & ARFTPb & ARFClb & ARFCIb & ARFCIb & ARFC $1 b$ \\
\hline
\end{tabular}




\begin{tabular}{|c|c|c|c|c|c|}
\hline \multirow[t]{3}{*}{11} & $\mathrm{ARFCO} 4$ & $\mathrm{ARFCPb}$ & $\mathrm{ARFCPb}$ & ARFCPb & $\mathrm{ARFCPb}$ \\
\hline & ARFTPa & ARFTPa & ARFTPa & ARFTPa & ARFTPa \\
\hline & ARFC1b & ARFTPb & ARFTPb & $\mathrm{ARFTPb}$ & ARFTPb \\
\hline \multirow[t]{3}{*}{12} & ARFCIb & ARFTPb & ARFTPb & ARFCOb & ARFCOb \\
\hline & ARFCP4 & ARFCP4 & ARFCP4 & ARFCP4 & ARFCP4 \\
\hline & ARFCP4 & $\mathrm{ARFCP} 4$ & ARFCP4 & ARFCP4 & ARFCP 4 \\
\hline \multirow[t]{3}{*}{13} & $\mathrm{ARFTPb}$ & ARFCIb & $\mathrm{ARFC} 1 \mathrm{~b}$ & $\mathrm{ARFTPb}$ & ARFTPb \\
\hline & ARFC14 & ARFCl 4 & ARFC14 & ARFTP4 & ARFTP4 \\
\hline & $\mathrm{ARFC14}$ & ARFC14 & ARFC14 & $\mathrm{ARFC1} 4$ & ARFC14 \\
\hline \multirow[t]{3}{*}{14} & $\mathrm{ARFCOb}$ & $\mathrm{ARFCOb}$ & $\mathrm{ARFCOb}$ & ARFC1b & ARFTO 4 \\
\hline & ARFTP4 & ARFTP4 & ARETP4 & ARFC14 & ARFC14 \\
\hline & ARFTP4 & ARFTP4 & ARFTP4 & ARFTP4 & ARFTP4 \\
\hline \multirow[t]{3}{*}{15} & $\mathrm{ARFCPa}$ & ARFT14 & ARFT14 & ARFT14 & ARFC1b \\
\hline & P2999 & P2999 & $\mathrm{ARFCOb}$ & $\mathrm{ARFCO} 4$ & $\mathrm{ARFCO} 4$ \\
\hline & ARFCOa & $\mathrm{ARFCOa}$ & ARFCOa & ARFCOa & ARFCOa \\
\hline \multirow[t]{3}{*}{16} & ARFCla & $\mathrm{ARFCPa}$ & $\mathrm{ARFCPa}$ & ARFT0 4 & ARFTI4 \\
\hline & $\mathrm{ARFCOb}$ & $\mathrm{ARFCOb}$ & P2999 & P2999 & P2999 \\
\hline & $\mathrm{ARFCOb}$ & $\mathrm{ARFCOb}$ & ARFCOb & $\mathrm{ARFCOb}$ & $\mathrm{ARFCOb}$ \\
\hline \multirow[t]{3}{*}{17} & ARFTPa & ARFCla & ARFT0 4 & $\mathrm{ARFCPa}$ & $\mathrm{ARFCOa}$ \\
\hline & $\mathrm{ARFCOa}$ & $\mathrm{ARFCO}$ & $\mathrm{ARFCOa}$ & $\mathrm{ARFCOb}$ & ARFCOb \\
\hline & P2999 & P2999 & P2999 & P2999 & P2999 \\
\hline \multirow[t]{3}{*}{18} & ARFT14 & ARFTPa & ARFCla & $\mathrm{ARFCOa}$ & ARFTOb \\
\hline & $\mathrm{ARFCO} 4$ & $\mathrm{ARFC0} 4$ & $\mathrm{ARFCO} 4$ & ARFCOa & $\mathrm{ARFCOa}$ \\
\hline & ARFC0 4 & $\mathrm{ARFCO} 4$ & $\mathrm{ARFCO} 4$ & $\mathrm{ARFC0} 4$ & $\mathrm{ARFC0} 4$ \\
\hline \multirow[t]{3}{*}{19} & ARFCOa & ARFCOa & ARFCOa & ARFCla & ARFTIb \\
\hline & ARFTIb & ARFTIb & ARFTIb & ARFTlb & ARFT14 \\
\hline & P1999 & ARETla & ARFT1a & ARFT1a & ARFTla \\
\hline \multirow[t]{3}{*}{20} & ARFT1b & ARFTO 4 & ARFTPa & ARFT1b & $\mathrm{ARFCPa}$ \\
\hline & ARFT1a & ARFTla & ARFT14 & ARFT14 & ARFT1b \\
\hline & P0999 & ARFT1b & ARFT1b & ARFTIb & ARFT1b \\
\hline \multirow[t]{3}{*}{21} & ARFT0 4 & ARFT1b & ARFTIb & ARFTPa & ARFCla \\
\hline & PA999 & ARFT14 & ARFT1a & ARFTla & ARFT1a \\
\hline & ANFPb & P0999 & ARFT14 & ARFT14 & ARFT14 \\
\hline \multirow[t]{3}{*}{22} & P1999 & ARFTOb & ARFTOb & ARFTOb & ARFTPa \\
\hline & ARFT14 & PA999 & ARFTO 4 & ARFT0 4 & ARFT0 4 \\
\hline & ANP2 03 & ARFT14 & P0999 & $\mathrm{EXP}$ & EXP \\
\hline \multirow[t]{3}{*}{23} & ARFTla & ARFTla & ARFTla & ARFTla & ARFTOa \\
\hline & P1999 & EXP & ARFTOb & ARFTOb & ARFTOb \\
\hline & AN1203 & EXP & EXP & $\mathrm{EX} 2$ & $\mathrm{EX} 2$ \\
\hline \multirow[t]{2}{*}{24} & ARFTOb & ARFTOa & ARFTOa & ARFTOa & ARFTla \\
\hline & $\mathrm{EXP}$ & ARFT0 4 & EXP & ARFTOa & ARFT0a \\
\hline
\end{tabular}




\begin{tabular}{|c|c|c|c|c|c|}
\hline & ARFTla & $\mathrm{EX} 2$ & $\mathrm{EX} 2$ & ARFTOb & ARFTOb \\
\hline \multirow[t]{3}{*}{25} & ARFT0a & EXP & EXP & EXP & EXP \\
\hline & EX2 & EX2 & PA999 & EXP & EXP \\
\hline & ARFT1b & P1999 & ARFTOb & ARFTOa & ARFTOa \\
\hline \multirow[t]{3}{*}{26} & EXP & EX2 & $\mathrm{EX} 2$ & $\mathrm{EX} 2$ & EX2 \\
\hline & P0999 & ARFTOb & ARFTOa & EX2 & EX2 \\
\hline & ARFT14 & ARFTOb & ARFTOa & ARFT0 4 & ARFT0 4 \\
\hline \multirow[t]{3}{*}{27} & $\mathrm{EX} 2$ & P1999 & P1999 & EX1 & EX1 \\
\hline & LS0063 & ARFTOa & $\mathrm{EX} 2$ & PA999 & PA999 \\
\hline & ANF1b & ARFTOa & ARFT0 4 & P0999 & P0999 \\
\hline \multirow[t]{3}{*}{28} & P0999 & P0999 & EX1 & NOCHANGE & NOCHANGE \\
\hline & ARFT0 4 & LSO0 063 & LS0063 & EXI & EX1 \\
\hline & EXP & ARFT0 4 & NOCHANGE & NOCHANGE & NOCHANGE \\
\hline \multirow[t]{3}{*}{29} & LSP0 63 & AN0223 & NOCHANGE & P1999 & P1999 \\
\hline & ARFTOb & LS0103 & EX1 & NOCHANGE & NOCHANGE \\
\hline & EX2 & ANP203 & EX1 & EX1 & EX1 \\
\hline \multirow[t]{3}{*}{30} & $\mathrm{ANF} O \mathrm{~b}$ & $\mathrm{ANF} O \mathrm{~b}$ & P0999 & P0999 & P0999 \\
\hline & ARFTOa & EX1 & NOCHANGE & LS0063 & LS0063 \\
\hline & LS0063 & AN1203 & LS0103 & LS0103 & LS0103 \\
\hline \multirow[t]{3}{*}{31} & AN0 223 & EX1 & ANFOb & $\mathrm{ANF} O \mathrm{~b}$ & $\mathrm{ANFPb}$ \\
\hline & ANP203 & NOCHANGE & LSO103 & LS0103 & LSFOb \\
\hline & LSP0 63 & $\mathrm{ANFPb}$ & P1999 & P1999 & ANFOa \\
\hline \multirow[t]{3}{*}{32} & ANFPb & NOCHANGE & ANO 223 & ANFPb & ANF $1 b$ \\
\hline & AN1203 & P1999 & AN0223 & LSFOb & LS0103 \\
\hline & ARFTOb & LS0103 & ANP203 & ANP2 03 & $\mathrm{ANF} O \mathrm{~b}$ \\
\hline \multirow[t]{3}{*}{33} & ANF1b & ANFPb & ANFPb & ANO 223 & ANFOb \\
\hline & ANF1b & ANP2 23 & LSFOb & ANO 223 & ANO 223 \\
\hline & ARFTOa & ANF1b & AN1203 & AN1203 & P1999 \\
\hline \multirow[t]{3}{*}{34} & ANFOa & ANF1b & ANF $1 b$ & ANF1b & ANO223 \\
\hline & ANFPb & P0999 & ANP2 23 & LSFOa & LSFOa \\
\hline & ARFT0 4 & NOCHANGE & ANF Pb & ANFOa & ANP2 03 \\
\hline \multirow[t]{3}{*}{35} & AN1223 & ANFOa & ANF0a & ANFOa & ANFOa \\
\hline & P3999 & AN1223 & LSF0a & ANP2 23 & ANP2 23 \\
\hline & LSF1a & EX1 & ANFPa & $\mathrm{ANF} O \mathrm{~b}$ & AN1203 \\
\hline \multirow[t]{3}{*}{36} & EX1 & LSP0 63 & ANO 213 & ANO 213 & ANO 213 \\
\hline & ANP223 & LSFOb & AN1223 & AN1223 & ANFOa \\
\hline & LSFPb & ANFPa & ANF1b & ANFPa & ANFPa \\
\hline \multirow[t]{3}{*}{37} & ANP223 & ANFPa & LSP0 63 & LSP0 63 & ANFPa \\
\hline & AN1223 & ANO 223 & ANF1a & ANFOa & AN1223 \\
\hline & LSF1b & LS0063 & ANF1a & ANFPb & ANF1a \\
\hline
\end{tabular}




\begin{tabular}{|c|c|c|c|c|c|}
\hline \multirow[t]{3}{*}{38} & NOCHANGE & ANF1a & ANFPa & ANFPa & ANEIa \\
\hline & LS0103 & ANP203 & ANFPa & ANF1a & ANFla \\
\hline & P3999 & ANF1a & $\mathrm{ANFO} \mathrm{b}$ & ANF1a & ANFPb \\
\hline \multirow[t]{3}{*}{39} & $\mathrm{ANFPa}$ & ANO213 & ANFla & ANFla & LSP0 63 \\
\hline & AN1213 & $\operatorname{AN} 1203$ & ANFOa & ANFPa & ANFPa \\
\hline & AN1223 & AN1223 & ANFOa & ANF1b & ANF1b \\
\hline \multirow[t]{3}{*}{40} & ANP2 13 & AN1223 & AN1223 & AN1223 & AN1 223 \\
\hline & ANF1a & ANF1b & ANF1b & ANFIb & ANF 1b \\
\hline & ANFPa & LSFOb & LSFOb & $\mathrm{LSFOb}$ & LSFOb \\
\hline \multirow[t]{3}{*}{41} & ANF1a & ANP2 23 & ANP2 23 & ANP2 23 & ANP2 23 \\
\hline & ANFPa & $\mathrm{ANFPb}$ & $\mathrm{ANFPb}$ & $\mathrm{ANFPb}$ & ANFPb \\
\hline & LS1063 & $\mathrm{ANF} O \mathrm{~b}$ & LS0063 & AN1223 & AN1223 \\
\hline \multirow[t]{3}{*}{42} & AN1213 & ANP2 13 & ANP2 13 & ANP2 13 & ANP2 13 \\
\hline & ANP213 & ANF1a & P1999 & P1999 & P1999 \\
\hline & ANFla & ANFOa & AN1223 & LSO0063 & LS0063 \\
\hline \multirow[t]{3}{*}{43} & C1001999 & AN1213 & AN1213 & AN1213 & AN1213 \\
\hline & C1001999 & ANFPa & P0999 & P0999 & P0999 \\
\hline & LSFPa & LSP06 63 & AN0 213 & ANO213 & AN0 213 \\
\hline \multirow[t]{3}{*}{44} & ANO 213 & C1001999 & $\mathrm{C} 1001999$ & ANO 203 & AN0203 \\
\hline & LSP103 & LSFOa & ANP2 03 & ANP2 03 & ANFOb \\
\hline & PA999 & P3999 & LSP0 63 & LSP063 & LSP 103 \\
\hline \multirow[t]{3}{*}{45} & ANP2 03 & AN0 203 & ANO203 & C1001999 & C1001999 \\
\hline & LS1103 & P3999 & AN1203 & AN1203 & ANP203 \\
\hline & LS0103 & LSFla & P3999 & P3999 & LS1103 \\
\hline \multirow[t]{3}{*}{46} & AN1203 & LS1063 & $\operatorname{LS} 1063$ & LS1063 & $\operatorname{LS} 1063$ \\
\hline & LSFOb & ANFOa & $\mathrm{ANFOb}$ & $\mathrm{ANFOb}$ & AN1203 \\
\hline & LSP103 & LSFPb & LSFla & LSFIa & LSP0 63 \\
\hline \multirow[t]{3}{*}{47} & LS1063 & ANP2 03 & ANP203 & ANP2 03 & C1000999 \\
\hline & LSFOa & AN1213 & AN1213 & AN1213 & AN1213 \\
\hline & LS1103 & LSF1b & LSF1b & LSFIb & P3999 \\
\hline \multirow[t]{3}{*}{48} & AN0 203 & AN1203 & AN1203 & AN1203 & ANP2 03 \\
\hline & AN0 223 & $\mathrm{ANFOb}$ & P3999 & P3999 & ANP213 \\
\hline & ANP2 23 & LSFOa & LSFPb & LSFPb & LSFIa \\
\hline \multirow[t]{3}{*}{49} & LSP103 & C1000999 & C1000999 & $\mathrm{C} 1000999$ & AN1203 \\
\hline & $\mathrm{EX} 1$ & ANP213 & ANP2 13 & ANP2 13 & P3999 \\
\hline & NOCHANGE & AN0203 & LSFOa & LSP103 & LSF1b \\
\hline \multirow[t]{3}{*}{50} & LS1103 & LSP103 & LSPIO3 & LSP103 & LSP103 \\
\hline & NOCHANGE & AN0203 & ANO203 & AN0 203 & AN0 203 \\
\hline & EX1 & AN0213 & ANO203 & LS1103 & LSFPb \\
\hline \multirow[t]{2}{*}{51} & $\mathrm{C} 1000999$ & LS1103 & LS1103 & LS1103 & LS1103 \\
\hline & ANFOb & LSP103 & LSP103 & LSP103 & LSPI03 \\
\hline
\end{tabular}




\begin{tabular}{|c|c|c|c|c|c|}
\hline \multirow[t]{3}{*}{52} & C3001999 & C3001999 & C3001999 & C3001999 & C3001999 \\
\hline & ANF0a & LS1103 & LS1103 & LS1103 & LS1103 \\
\hline & LSFOa & LSFPa & LS1103 & LSFOa & LSFOa \\
\hline \multirow[t]{3}{*}{53} & C3000999 & C3000999 & C3000999 & C3000999 & C3000999 \\
\hline & ANO203 & C1001999 & C1001999 & C1001999 & C1001999 \\
\hline & ANO203 & LSP103 & LS1063 & LS1063 & LS1063 \\
\hline \multirow[t]{3}{*}{54} & LSFPb & LSFPb & LSFPb & $\mathrm{LSFPb}$ & LSFPb \\
\hline & C3001999 & C3001999 & $\mathrm{C} 1000999$ & $\mathrm{C} 1000999$ & $\mathrm{C} 1000999$ \\
\hline & ANO223 & LS1103 & LSFPa & LSFPa & LSFPa \\
\hline \multirow[t]{3}{*}{55} & LSF1b & LSFIb & LSFIb & LSF1b & LSFIb \\
\hline & LSFPb & C1000999 & C3001999 & C3001999 & C3001999 \\
\hline & ANFOb & PA999 & PA999 & PA999 & PA999 \\
\hline \multirow[t]{3}{*}{56} & LS0063 & LSO0063 & LS0063 & LS0063 & LS0063 \\
\hline & LSFIb & LSFPb & $\mathrm{LSFPb}$ & LSFPb & LSFPb \\
\hline & ANFOa & ANP2 23 & ANO 223 & AN0223 & ANO223 \\
\hline \multirow[t]{3}{*}{57} & PA999 & PA999 & PA999 & PA999 & PA999 \\
\hline & LSFPa & LSFPa & LSFPa & LSFPa & LSFPa \\
\hline & AN0 213 & AN0223 & ANP223 & ANP2 23 & ANP2 23 \\
\hline \multirow[t]{3}{*}{58} & LS0103 & LS0103 & P3999 & P3999 & P3999 \\
\hline & C1000999 & LSF1b & LSF1b & LSF1b & LSF1b \\
\hline & C1000999 & $\mathrm{C} 1000999$ & C1000999 & C1000999 & $\mathrm{C} 1000999$ \\
\hline \multirow[t]{3}{*}{59} & P3999 & P3999 & LS0103 & LS0103 & LS0103 \\
\hline & LSF1a & LSFla & LSFIa & LSF1a & LSFIa \\
\hline & C1001999 & C1001999 & $\mathrm{C} 1001999$ & C1001999 & $\mathrm{C} 1001999$ \\
\hline \multirow[t]{3}{*}{60} & LSFOb & LSFOb & LSFOb & LSFOb & LSFOb \\
\hline & C3000999 & C3000999 & C3000999 & C3000999 & C3000999 \\
\hline & C3000999 & C3000999 & C3000999 & C3000999 & C3000999 \\
\hline \multirow[t]{3}{*}{61} & LSFOa & LSFOa & LSFOa & LSFOa & LSFOa \\
\hline & ANO213 & AN0213 & LSP0 63 & LSP063 & LSP0 63 \\
\hline & C3001999 & C3001999 & C3001999 & C3001999 & C3001999 \\
\hline \multirow[t]{3}{*}{62} & LSFPa & LSFPa & LSFPa & LSFPa & LSFPa \\
\hline & LSP063 & LSP063 & ANO 213 & LS1063 & LS1063 \\
\hline & ANP213 & ANP2 13 & ANP213 & AN1213 & ANP213 \\
\hline \multirow[t]{3}{*}{63} & LSF1a & LSFla & LSFla & LSF1a & LSF1a \\
\hline & LS1063 & LS1063 & LS1063 & ANO 213 & ANO213 \\
\hline & AN1213 & AN1213 & AN1213 & ANP213 & AN1213 \\
\hline
\end{tabular}




\section{Forecasting performance broken down by category of series}

Numbers in parentheses are the number of time series in each category

For each forecast, the first row corresponds to one-step ahead forecasts; the second row, to 6 -step ahead forecasts; the third row, to 12 -step ahead forecasts.

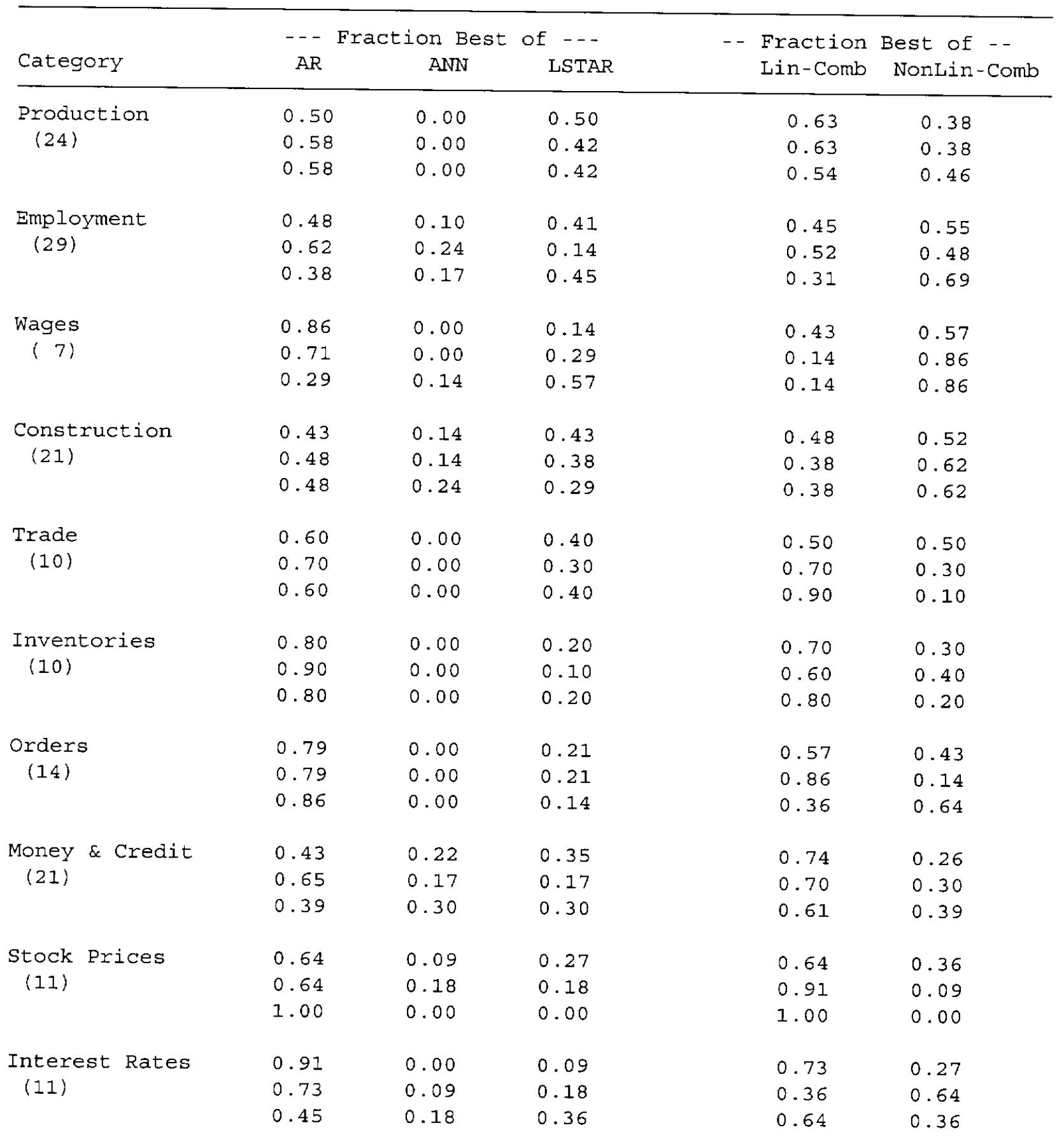




$\begin{array}{llllll}\text { Exchange Rates } & 0.83 & 0.00 & 0.17 & 0.67 & 0.33 \\ (6) & 0.83 & 0.00 & 0.17 & 0.33 & 0.67 \\ & 0.67 & 0.17 & 0.17 & 0.33 & 0.67 \\ \text { Producer Prices } & 0.38 & 0.19 & 0.44 & & \\ (16) & 0.69 & 0.06 & 0.25 & 0.38 & 0.63 \\ & 0.63 & 0.13 & 0.25 & 0.75 & 0.25 \\ & & & & 0.38 & 0.63 \\ \text { Consumer Prices } & 0.50 & 0.13 & 0.38 & 0.63 & 0.38 \\ (16) & 0.50 & 0.00 & 0.50 & 0.69 & 0.31 \\ & 0.44 & 0.06 & 0.50 & 0.75 & 0.25 \\ \text { Consumption } & 0.40 & 0.20 & 0.40 & 0.40 & 0.60 \\ (5) & 0.60 & 0.00 & 0.40 & 0.80 & 0.20 \\ & 0.80 & 0.00 & 0.20 & 1.00 & 0.00 \\ \text { Miscellaneous } & 0.50 & 0.07 & 0.43 & 0.57 & 0.43 \\ (14) & 0.79 & 0.00 & 0.21 & 0.64 & 0.36 \\ & 0.79 & 0.14 & 0.07 & 0.71 & 0.29\end{array}$

Notes: The forecasts being compared are, in the first numerical column, the recursive PLS-selected AR forecast; in the second column, the recursive PLS-selected ANN forecast; in the third column, the recursive PLS-selected LSTAR forecast; in the fourth column, the C2001999 forecast; and in the fifth column, the C3001999 forecast. 